\title{
De las violaciones masivas a los patrones estructurales: nuevos enfoques y clásicas tensiones en el Sistema Interamericano de Derechos Humanos
}

\author{
VÍCTOR ABRAMOVICH*
}

\begin{abstract}
SUMARIO: I. INTRODUCCIÓN.- II. CAMBIO DE ROLES EN NUEVOS ESCENARIOS POLÍTICOS.- III. EL SIDH COMO ESCENARIO DEL ACTIVISMO TRANSNACIONAL Y DE LA ACCIÓN POLÍTICA DE LOS GOBIERNOS.- IV. UNA AGENDA AMPLIADA. LA EXCLUSIÓN Y LA DEGRADACIÓN INSTITUCIONALES.- V. LOS DERECHOS EN UN ESCENARIO DE DESIGUALDAD ESTRUCTURAL.- VI. OBJECIONES A LA AMPLIACIÓN DE LA AGENDA Y LOS MÁRGENES DE LA PROTECCIÓN INTERNACIONAL.- VII. ARTICULACIÓN Y TENSIÓN ENTRE EL ROL JUDICIAL Y EL ROL POLÍTICO.- VIII. LA EFECTIVIDAD DE LAS DECISIONES. LA ARTICULACIÓN CON LOS SISTEMAS LOCALES DE JUSTICIA.- IX. CONCLUSIÓN.
\end{abstract}

\section{INTRODUCCIÓN}

El Sistema Interamericano de Derechos Humanos (SIDH) ha incidido, durante la última década, en el proceso de internacionalización de los sistemas jurídicos en varios países de América Latina. En ese período, más países han aceptado la competencia de la Corte Interamericana - como México y Brasil-y le han concedido a la Convención Americana rango constitucional o superior a las leyes en sus sistemas jurídicos. Los abogados, los jueces, los operadores jurídicos, los funcionarios y los activistas sociales han aprendido mucho más sobre la lógica de funcionamiento del SIDH y han comenzado a utilizarlo ya no de manera extraordinaria o selectiva. También han comenzado a citar sus decisiones y argumentar con sus precedentes en las cortes locales y en los debates sobre políticas públicas. Esto llevó a que la jurisprudencia del SIDH se comenzara a aplicar gradualmente en las decisiones de los tribunales constitucionales y las cortes supremas nacionales, y en los últimos tiempos, aun de manera más débil, en la formulación de algunas políticas estatales. Este proceso de incorporación en el ámbito nacional del Derecho internacional de los derechos humanos produjo importantes cambios institucionales.

Como ejemplo basta señalar que los estándares jurídicos desarrollados por la jurisprudencia de la Comisión Interamericana (CIDH o

* Segundo Vicepresidente de la Comisión Interamericana de Derechos Humanos. Relator de la Comisión Interamericana para Colombia, Cuba, Guatemala, Nicaragua y Relator Especial sobre derechos de las mujeres. Profesor de Derechos Humanos de la Facultad de Derecho de la Universidad de Buenos Aires y de la Universidad Nacional de Lanús. 
Comisión) y de la Corte Interamericana (Corte IDH o Corte) sobre invalidez de las leyes de amnistía de graves violaciones de derechos humanos le dieron sostén legal a la apertura de los procesos judiciales contra los responsables de crímenes de lesa humanidad en Perú y Argentina. Esos estándares fijados en el caso Barrios Altos contra Perú han sido definitivos para invalidar la ley de autoamnistía del régimen de Fujimori y para sostener el juzgamiento de los crímenes cometidos durante su gobierno ${ }^{1}$, pero la decisión del caso ha tenido un efecto cascada y ha incidido en la argumentación legal de los tribunales argentinos al invalidar las leyes de obediencia debida y punto final ${ }^{2}$. La jurisprudencia interamericana también está presente, aunque de manera más tímida, en decisiones recientes de los tribunales superiores de Chile ${ }^{3}$. Resulta además relevante en los debates sobre reducción de penas en el marco del proceso de paz con los grupos paramilitares en Colombia, así como en el tratamiento político y judicial de los temas pendientes de justicia transicional en Guatemala, El Salvador, Honduras y Uruguay. Recientemente se han presentado ante la Corte IDH casos sobre crímenes de lesa humanidad cometidos durante el período de la «guerra fría» en Brasil ${ }^{4}$, Bolivia $^{5}$ y México, lo que ha incidido en las discusiones políticas y judiciales locales ${ }^{6}$.

Este proceso, sin embargo, no es lineal. Enfrenta problemas y obstáculos, y ha sufrido también algunos retrocesos. El SIDH, por lo demás, se encuentra en un período de fuertes debates que procuran definir sus prioridades temáticas y su lógica de intervención en un nuevo escenario político-regional de democracias deficitarias, diferente del escenario político que lo vio nacer y dar sus primeros pasos en el marco de los procesos dictatoriales en Sudamérica durante los años setenta y los conflictos armados centroamericanos de los ochenta.

Este artículo procura presentar un panorama general de algunas discusiones estratégicas que tienen lugar tanto en el interior de los órganos interamericanos como de la comunidad de derechos humanos acerca del rol del SIDH en el escenario político-regional.

1 Véase,entreotroscasos deaplicacióndomésticadelasentenciadeBarrios Altosc.Perú,elcaso «Santiago Martín Rivas". Tribunal Constitucional de Perú, 29 de noviembre de 2005.

2 «Simón, Julio, Héctor y otros». Corte Suprema de Argentina, 14 de junio de 2005.

3 La Corte IDH invalidó la autoamnistía chilena en el caso Almonacid Arellano y otros vs. Chile, Corte IDH, 26 deseptiembrede2006. Sincitaresteprecedente, puedenencontrarseargumentosdeDerechointernacional humanitarioydeDerechoshumanosinternacionalenlosfundamentosdelasdecisionesdelaCorteSuprema chilena que invalidaron constitucionalmenteesa norma. Véase «Hechos acaecidos en el regimiento Cerro Chena». Segunda Sala de la Corte Suprema de Chile, 13 de marzo de 2007.

4 Véase la demanda de la CIDH ante la Corte IDH, Julio Gómez Lund y otros (Guerrilla do Araguaia), caso 11.552, contra República Federativa de Brasil, 26 de marzo de 2009.

5 Véase la demanda de la CIDH ante la Corte IDH, Renato Ticona Estrada y otros. Caso 12.527, contra República de Bolivia, 8 de agosto de 2007.

6 Véase la demanda de la CIDH ante la Corte IDH, Rosendo Radilla Pacheco. Caso 12.511 contra los Estados Unidos Mexicanos, 15 de marzo de 2008. 


\section{CAMBIO DE ROLES EN NUEVOS ESCENARIOS POLÍTICOS}

Es indudable que el rol de los órganos del sistema, tanto de la Comisión como de la Corte, ha variado a la luz del cambio de los escenarios políticos en el continente americano.

En sus inicios, el SIDH debió enfrentar violaciones masivas y sistemáticas cometidas bajo sistemas de terrorismo de Estado o en el marco de violentos conflictos armados internos. Su rol fue, en síntesis, el de un último recurso de justicia para las víctimas de esas violaciones, quienes no podían acudir a sistemas internos de justicia por encontrarse estos devastados o manipulados. En aquellos tiempos iniciales de asfixia política en el interior de los Estados nacionales, los informes sobre países de la Comisión sirvieron para documentar situaciones con rigor técnico y para legitimar las denuncias de las víctimas y sus organizaciones, y exponer y desgastar la imagen de los dictadores en la esfera local e internacional.

Luego, durante las transiciones postdictatoriales de la década de 1980 y principios de la de 1990, el SIDH tuvo ya un sentido más amplio, pues procuró acompañar los procesos políticos dirigidos al tratamiento del pasado autoritario y a sus secuelas en las instituciones democráticas. En este período, el SIDH comenzó a delinear los principios medulares acerca del derecho a la justicia, a la verdad y a la reparación ante graves violaciones, masivas y sistemáticas, de derechos humanos. Fijó los límites de las leyes de amnistía. Sentó las bases para la protección estricta de la libertad de expresión y la prohibición de la censura previa. Invalidó los tribunales militares para juzgar civiles y casos de derechos humanos, con lo que limitó un espacio de acción de las fuerzas militares que eran todavía actores de veto en las transiciones y que procuraban impunidad por los crímenes del pasado. Protegió el hábeas corpus, las garantías procesales, el orden constitucional democrático y la división de poderes estatales ante la posibilidad todavía latente en la época de regresiones autoritarias y de abusos de los Estados de excepción ${ }^{7}$. Interpretó el alcance de las limitaciones que impone la Convención a la aplicación de la pena de muerte; invalidó la pena de muerte a menores de edad y enfermos mentales y la aplicación de pena de muerte mandatoria, y fijó estándares estrictos de debido proceso como garantía para limitar la arbitrariedad de los tribunales en la aplicación de la pena capital. Abordó, además, temas sociales que expresaban rezagos discriminatorios en la región, por ejemplo al afirmar la igualdad ante la ley de las mujeres en sus derechos familiares y matrimoniales, y los derechos hereditarios de los hijos nacidos fuera del matrimonio que los códigos civiles americanos consideraban todavía como «ilegítimos».
DE LAS

VIOLACIONES

MASIVAS A

LOS PATRONES

ESTRUCTURALES:

NUEVOS

ENFOQUES

Y CLÁSICAS

TENSIONES EN

EL SISTEMA

INTERAMERICANO

DE DERECHOS

HUMANOS 
Durante la década de 1990, además, enfrentó con firmeza regímenes de terrorismo de Estado, como el régimen peruano de Alberto Fujimori, al documentar y denunciar, como lo había hecho en Sudamérica en los setentas, prácticas sistemáticas de desapariciones y torturas, así como la impunidad que apañaba aquellos crímenes de Estado. También fue un actor relevante en el seguimiento de las graves violaciones de los derechos humanos y del Derecho internacional humanitario cometidas en el marco del conflicto armado interno en Colombia.

El actual escenario regional es sin duda más complejo. Muchos países de la región dejaron atrás sus experiencias de transición, pero no lograron consolidar sus sistemas democráticos. Se trata de un escenario de democracias representativas que han dado algunos pasos importantes, por ejemplo en la mejora de los sistemas electorales, el respeto a la libertad de prensa y el abandono de las prácticas de violencia política, pero que presentan serias deficiencias institucionales, tales como sistemas de justicia inefectivos, y sistemas policiales y penitenciarios violentos. Se trata de democracias que conviven, además, con niveles alarmantes de desigualdad y exclusión, y que provocan a su vez un clima de constante inestabilidad política.

En este nuevo escenario, los órganos del SIDH han procurado no solo reparar a las víctimas en casos particulares, sino también fijar un cuerpo de principios y estándares con el propósito de incidir en la calidad de los procesos democráticos y en el fortalecimiento de los principales mecanismos domésticos de protección de derechos. El desafío del SIDH en esta etapa es mejorar las condiciones estructurales que garantizan la efectividad de los derechos en el nivel nacional. Este enfoque tiene como presupuesto el carácter subsidiario de los mecanismos de protección internacional frente a las garantías de esos derechos en los propios Estados. De tal modo, reconoce los límites claros de la supervisión internacional y, al mismo tiempo, resguarda el necesario margen de autonomía de los procesos políticos nacionales para alcanzar mejores niveles de realización y vigencia de los derechos humanos.

Durante la etapa de las transiciones, como dijimos, el SIDH contribuyó a algunos debates institucionales, tales como la subordinación de las fuerzas armadas al control civil y su intervención en asuntos de seguridad interna, y al alcance de los fueros y las competencias de la justicia penal militar. Estos asuntos tenían una vinculación directa con el tratamiento de las violaciones del pasado, pues implicaban definir el poder de veto o de presión de los militares en las transiciones. En la etapa posterior a estas, la agenda institucional se amplía considerablemente por el tipo de asuntos que llegan a conocimiento del SIDH.

Un lugar central en la nueva agenda del SIDH lo ocupan los temas relativos al funcionamiento de los sistemas de administración de justicia que tienen impacto o relación con el ejercicio de los derechos humanos. 
No solo se ocupa de las garantías procesales de los imputados en procesos criminales, sino también del derecho de ciertas víctimas que no logran un acceso igualitario a la justicia y que sufren patrones estructurales de impunidad frente a determinados crímenes estatales, como la violencia de las agencias policiales y penitenciarias. Las estrategias de lucha contra el crimen organizado y el terrorismo internacional han recuperado algunas discusiones de la agenda transicional relativas a la administración de justicia, como el debate sobre la competencia del fuero militar. En ese sentido, el seguimiento de las políticas de seguridad ciudadana ha cobrado centralidad. También lo han hecho las garantías de independencia e imparcialidad de tribunales y diferentes cuestiones relacionadas con la amplia protección convencional del debido proceso y el derecho a la protección judicial, incluso en relación con la tutela judicial de derechos sociales.

Otra línea de problemas institucionales examinados por el SIDH en la etapa «post-transiciones» está representada por aquellos temas vinculados con la preservación de la esfera público-democrática en los países de la región, esto desde temas relacionados con libertad de expresión, libertad de prensa, acceso a la información pública, derecho de reunión y asociación, libertad de manifestar y, de manera incipiente, algunos temas relativos a igualdad y debido proceso judicial en materia electoral.

Por lo demás, un aspecto prioritario de la agenda del SIDH en esta etapa lo ocupan nuevas demandas de igualdad de grupos y colectivos que se proyectan sobre muchos de los asuntos institucionales que antes mencionamos, pues abarcan situaciones de sectores excluidos que ven afectados sus derechos de participación y expresión, y que sufren patrones de violencia institucional o social u obstáculos en el acceso a la esfera pública, al sistema político o a la protección social o judicial. Volveremos específicamente sobre esta cuestión en los puntos IV y V.

Además de la ampliación de la agenda, en esta tercera etapa también se observa un cambio en la formas de intervención del SIDH y en el efecto que tienen sus decisiones en la esfera local.

La jurisprudencia del SIDH ha tenido un considerable impacto en la jurisprudencia de los tribunales nacionales que aplican las normas del Derecho internacional de los derechos humanos. Es importante considerar que las decisiones adoptadas por los órganos del sistema en un caso particular tienen un valor heurístico de interpretación de los tratados aplicables al conflicto, que trasciende a las víctimas afectadas en tal proceso. Esa jurisprudencia internacional suele ser utilizada como guía para las decisiones que adoptan luego a nivel doméstico los tribunales nacionales, que procuran así evitar que los Estados puedan ser expuestos a peticiones y eventuales condenas ante instancias internacionales. Este proceso de globalización de estándares de derechos humanos, si bien no ha alcanzado igual grado de desarrollo en toda la región y está sujeto en ocasiones a la precariedad

DE LAS

VIOLACIONES

MASIVAS A

LOS PATRONES

ESTRUCTURALES:

NUEVOS

ENFOQUES

Y CLÁSICAS

TENSIONES EN

EL SISTEMA

INTERAMERICANO

DE DERECHOS

HUMANOS 
de los sistemas de justicia, ha tenido una indudable incidencia positiva en la transformación de esos mismos sistemas judiciales y ha generado una mayor atención en las autoridades estatales ante los desarrollos del SIDH. Así, la jurisprudencia fijada por la Comisión, y en especial por la Corte, ha incidido en diversos cambios jurisprudenciales en los países del área, en temas relacionados con la débil y deficitaria institucionalidad de las democracias latinoamericanas. Podemos mencionar, por ejemplo, la jurisprudencia sobre la despenalización del desacato y de las críticas emitidas por la prensa, el acceso a la información pública y los límites en la persecución penal de manifestaciones públicas pacíficas; la fijación de límites y condiciones objetivas para el uso de la prisión preventiva, de las facultades de detención de las policías y de la fuerza pública; la determinación de pautas para un sistema penal diferenciado para los menores de edad sobre el derecho a apelar ante un tribunal superior las condenas penales; la participación de las víctimas de crímenes de Estado en los procesos judiciales; el reconocimiento de mínimos derechos al debido proceso en la esfera administrativa y la revisión judicial de actos administrativos, así como de garantías básicas en los procesos de remoción de magistrados, entre otros asuntos de gran relevancia para el funcionamiento de las instituciones y orden constitucional en los Estados ${ }^{8}$.

Ahora bien, la incidencia del SIDH no se limita al impacto de su jurisprudencia sobre la jurisprudencia de los tribunales locales. Otra vía importante para el fortalecimiento de la institucionalidad democrática en los Estados surge de la capacidad del SIDH de influir en la orientación general de algunas políticas públicas y en sus respectivos procesos de formulación, implementación, evaluación y fiscalización. Así, es común observar que las decisiones individuales adoptadas en un caso suelan imponer a los Estados obligaciones de formular políticas para reparar la situación que da origen a la petición e incluso establezcan el deber de abordar los problemas estructurales que están en la raíz del conflicto analizado.

Por lo general, la imposición de estas obligaciones positivas está precedida por el examen bajo estándares jurídicos de las políticas implementadas o de la falta de acción (omisión) del Estado. Esas obligaciones pueden consistir en cambios de políticas existentes, reformas legales, implementación de procesos participativos para formular nuevas políticas públicas y, muchas veces, en la reversión de determinados patrones de comportamiento que caracterizan el accionar de ciertas instituciones del Estado que promueven violaciones — por ejemplo, violencia policial, abuso y tortura en prisiones; aquiescencia del Estado frente a situaciones de violencia doméstica; políticas de desplazamiento forzoso de población

8 Méndez, Juan E. y Javier MariezcurrenA. «Human Rights in Latin America and The Caribbean. A Regional Perspective». Documento enviado para Human Development Report 2000. Human Rights and Human Development. En Víctor Abramovich, AlbertoBovinoy Christian Courtis (compiladores). Laaplicacióndelos tratados sobre derechos humanos en el ámbito local. La experiencia de una década. Buenos Aires: CELS y Editores del Puerto, 2007. 
en el marco de conflictos armados; desalojos masivos de poblaciones indígenas de sus tierras ancestrales; entre otros-.

Además, en el marco de casos individuales, el SIDH —y en especial la Comisión - promueve procesos de solución amistosa o negociaciones entre peticionarios y Estados. Durante estos, los Estados muchas veces se comprometen a implementar dichas reformas institucionales o crean mecanismos de consulta con la sociedad civil para la definición de políticas. Así, en el marco de diversos procesos de soluciones amistosas, se ha conseguido que algunos Estados, por ejemplo:

- modifiquen sus leyes;

- deroguen la figura del desacato que permitía la penalización de la crítica política;

- creen procedimientos para averiguar la verdad sobre el paradero de personas desaparecidas;

- implementen programas masivos de reparación para víctimas de violaciones de derechos humanos o programas de reparación colectiva para comunidades afectadas por la violencia;

- implementen programas públicos de protección de víctimas, testigos y defensores de derechos humanos;

- revisen procesos penales en los que se había dictado condenas sin debido proceso o revean el cierre de causas penales en las que se había absuelto de manera fraudulenta a agentes del Estado acusados de violar derechos humanos;

- adecuen normas del Código Civil que discriminaban a hijos nacidos fuera del matrimonio o que discriminaban a las mujeres ante sus derechos en el matrimonio;

- implementen leyes de cupos para las mujeres en los procesos electorales o leyes sobre violencia contra las mujeres;

- implementen protocolos para la realización de abortos no punibles, o;

- deroguen leyes migratorias que afectaban derechos civiles de los inmigrantes.

La CIDH realiza, asimismo, recomendaciones sobre políticas públicas en sus informes generales por países. En ellos analiza situaciones concretas de violaciones y brinda recomendaciones que orientan políticas estatales sobre la base de estándares jurídicos?.

DE LAS

VIOLACIONES

MASIVAS A

LOS PATRONES

ESTRUCTURALES:

NUEVOS

ENFOQUES

Y CLÁSICAS

TENSIONES EN

EL SISTEMA

INTERAMERICANO

DE DERECHOS

HUMANOS 
La Comisión también puede emitir informes temáticos que abarcan cuestiones de interés regional o que conciernen a varios Estados. Este tipo de informes posee un enorme potencial para fijar estándares y principios y para relevar situaciones colectivas o problemas estructurales que pueden no estar debidamente reflejados en la agenda de casos individuales. Poseen, además, una perspectiva promocional más clara que los informes por país, que suelen ser vistos como mecanismos de exposición de los Estados ante la comunidad internacional y sus audiencias locales. El proceso de elaboración de los informes temáticos a su vez permite a la Comisión dialogar con actores sociales locales e internacionales relevantes para una determinada temática; recabar la opinión de expertos, de agencias de cooperación e instituciones financieras internacionales; de órganos políticos y técnicos de la OEA; e iniciar vínculos con los funcionarios encargados de generar en definitiva políticas en los campos analizados $^{10}$.

Por último, la Corte Interamericana de Derechos Humanos puede emitir opiniones consultivas que sirven para examinar problemas concretos más allá de los casos contenciosos y fijar el alcance de las obligaciones estatales que emanan de la Convención y de otros tratados de derechos humanos aplicables en el ámbito regional, tales como la situación jurídica de los trabajadores migrantes y los derechos humanos de niños y adolescentes. A través de estas opiniones consultivas, en ocasiones la Corte ha intentado fijar marcos jurídicos para el desarrollo de políticas. Así, por ejemplo, en la Opinión Consultiva 18, procura definir una serie de principios que deben orientar las políticas migratorias de los Estados y, en especial, el reconocimiento de ciertos derechos sociales básicos a los inmigrantes en situación irregular. En la Opinión Consultiva 17, procura orientar las políticas dirigidas a la infancia, al imponer límites a las políticas criminales dirigidas a los niños.

\section{III.EL SIDH COMO ESCENARIO DEL ACTIVISMO TRANSNACIONAL Y DE LA ACCIÓN POLÍTICA DE LOS GOBIERNOS}

Al mismo tiempo, el SIDH, y tanto la Comisión como la Corte, se han convertido gradualmente en un escenario privilegiado de activismo de la sociedad civil, que ha desplegado estrategias innovadoras para aprovechar, en el ámbito nacional, la repercusión internacional de

\footnotetext{
10 Sobre el valor de los informes temáticos como herramientas de incidencia de la CIDH en el contexto de democracias deficientes en la región, véase el preciso análisis de Tom Farer. "The Future of the InterAmerican Comission on Human Rights: Promotion versus Exposure». En Juan E. Méndez y Francisco Cox (editores). El futuro del sistema interamericano de protección de los derechos humanos. San José: Instituto Interamericano de Derechos Humanos, 1998, pp.515-536. Comoejemplo de este tipo de informes temáticos, véase CIDH, «Informesobrelasituacióndelos defensorasydefensoresdederechoshumanosen las Américas", 7/03/06. Comomodelos de informestemáticos peroaplicadosauncontextonacional, véase $\mathrm{CIDH}$, «Lasmujeresfrentealaviolenciayladiscriminación derivadasdelconflictoarmadoen Colombia»,18 de octubre de 2006; CIDH, «Informe sobre los derechos de las mujeres en Chile: la igualdad en la familia, el trabajoylapolítica»,27/03/09; CIDH, «Elderechodelasmujeresaunavidalibredeviolenciaydiscriminación en Haití», 10 de marzo de 2009.
} 
los casos y situaciones denunciadas en las denominadas estrategias de bumerán ${ }^{11}$.

Las organizaciones sociales se han valido de este escenario internacional no solo para denunciar violaciones y hacer visibles ciertas prácticas estatales cuestionadas, sino también para alcanzar posiciones privilegiadas de diálogo con los gobiernos o con aliados en el interior de estos, y para revertir las relaciones de fuerza y alterar la dinámica de algunos procesos políticos. Ello, en ocasiones, ha facilitando la apertura de espacios de participación e incidencia social en la formulación e implementación de políticas y en el desarrollo de reformas institucionales. También han sido estas organizaciones sociales las que han incorporado con mayor frecuencia los estándares jurídicos fijados por el SIDH como parámetro para evaluar y fiscalizar acciones y políticas de los Estados, y en ocasiones para impugnarlas ante los tribunales nacionales o ante la opinión pública local e internacional.

En los países de América Latina, muchas organizaciones de derechos humanos y otras organizaciones sociales que actúan con una perspectiva de derechos, como organizaciones feministas, de control ciudadano, ambientales, y defensoras de usuarios y consumidores, entre otras, además de fiscalizar las acciones estatales, han incorporado nuevas estrategias de diálogos y negociación con los gobiernos, a fin de incidir en la orientación de sus políticas y de lograr transformaciones en el funcionamiento de las instituciones públicas. El cambio de perspectiva apunta a incorporar al trabajo tradicional de denuncia de violaciones una acción preventiva y de promoción capaz de evitarlas.

De tal modo, la comunidad de usuarios del SIDH han crecido considerablemente en cantidad y se ha vuelto más variada, plural y compleja. El SIDH ha comenzado a ser utilizado de manera mucho más frecuente por las organizaciones sociales locales, y ya no solo por las clásicas organizaciones internacionales que contribuyeron a darle forma en los primeros tiempos, o por aquellas que se han especializado en sus mecanismos. Algunos de los casos más exitosos en términos de cambios sociales han sido promovidos y sostenidos por coaliciones o alianzas de «escala múltiple», esto es, con capacidad de actuar en diferentes esferas locales e internacionales. Por lo general, se trata de coaliciones formadas por organizaciones internacionales o regionales con experiencia en el uso del SIDH, y de organizaciones locales con capacidad de movilización social, diálogo e incidencia en los gobiernos y en la opinión pública. Este tipo de

11 Véanse al respecto las siguientes obras: NeLSON, Paul y Ellen Dorsey. «New Rights Advocacy in a Global Public Domain». European Journal of International Relations, junio de 2006. RISSE, Thomas y Kathryn SIKKINK. "TheSocialization of InternationalHumanRightsNormsintoDomesticPractices:Introduction».EnT.Risse, S.C. Ropp y K. Sikkink. The Power of Human Rights. International Norms and Domestic Change. Cambridge Studies in International Relations. Cambridge: Cambridge University Press, 1999, pp. 1-39. SıKKINK, K. «La dimensión transnacional de los movimientos sociales». En E. Jelin (compiladora). Más allá de la nación: las escalas múltiples de los movimientos sociales. Buenos Aires: Libros del Zorzal, 2003, pp.301-335.

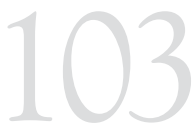

DE LAS

VIOLACIONES

MASIVAS A

LOS PATRONES

ESTRUCTURALES:

NUEVOS

ENFOQUES

Y CLÁSICAS

TENSIONES EN

EL SISTEMA

INTERAMERICANO

DE DERECHOS

HUMANOS 
alianzas ha permitido mejorar la articulación de las estrategias desplegadas en el escenario internacional con las empleadas en el terreno local.

Al mismo tiempo, muchas organizaciones locales han adquirido gradualmente experiencia suficiente para actuar de manera independiente en el SIDH, y en ocasiones han impulsado alianzas entre sus pares de otros países del área para impulsar en el SIDH temas regionales de interés común, como la brutalidad policial, o el acceso a la información pública o la violencia contra las mujeres ${ }^{12}$. Así, por ejemplo, una red de organizaciones especializadas en temas de violencia policial y sistema penal han promovido que la Comisión se involucre en la preparación de un informe temático sobre seguridad ciudadana y derechos humanos, que fije estándares claros para orientar políticas de seguridad democráticas en toda la región. También ha sido resultado de la incidencia de redes de organizaciones sociales el reciente informe sobre la situación de los defensores de derechos humanos elaborado por la Comisión y el proceso de seguimiento de sus recomendaciones en los Estados. Una red de organizaciones no gubernamentales y medios de prensa comunitarios promueve la adopción por la CIDH de una serie de principios mínimos para la regulación de la radiodifusión.

Además de las organizaciones con perfil jurídico, que suelen representar a víctimas o a grupos de víctimas, determinadas acciones ante el SIDH involucran con frecuencia organizaciones de base o comunitarias que integran también redes o alianzas con aquellas, para impulsar casos, audiencias temáticas o promover informes de la CIDH. El trabajo de las relatorías de la $\mathrm{CIDH}$ sobre derechos de los pueblos indígenas y sobre discriminación racial ha ampliado considerablemente la utilización del SIDH por líderes de pueblos indígenas y de comunidades afroamericanas. También ha aumentado la participación de sindicatos en alianza con organizaciones de derechos humanos para plantear temas relativos a libertad sindical, y justicia laboral y previsional.

En los países donde el SIDH es más conocido, como Argentina y Perú, por ejemplo, abogados particulares han incorporado este escenario internacional como una nueva instancia en el litigio de variados temas, por ejemplo asuntos previsionales relativos a la demora de los procesos y a la aplicación de leyes de emergencia, o las garantías de los imputados en procesos criminales.

Pero el SIDH también ha sido utilizado de manera activa por algunos Estados o por organismos públicos con competencia en derechos humanos, para iluminar ciertas cuestiones e impulsar agendas nacionales o regionales. Estos procesos se han favorecido con la paulatina conformación de una burocracia estatal especializada en el manejo de estos temas, 
que suele incidir en algunos aspectos de la gestión pública, tales como secretarias y comisiones de derechos humanos, direcciones especializadas en las cancillerías, defensorías del pueblo, procuradurías de derechos humanos, defensorías públicas y fiscalías especializadas, entre otras. En ocasiones, cuando los gobiernos ponen en práctica políticas claras en esta materia, un caso en el SIDH suele ser considerado como una oportunidad de incidencia política, por las áreas interesadas del mismo gobierno, para superar resistencias en el propio Estado o en otros sectores sociales. Esto puede observarse con claridad en algunos procesos de solución amistosa que motivaron cambios en la legislación y en políticas nacionales ${ }^{13}$. En ocasiones, los peticionarios son también agencias públicas independientes que litigan y en ocasiones negocian con la representación del gobierno. El ejemplo frecuente son las defensorías públicas penales, que se han convertido en usuarios importantes del SIDH.

Algunos Estados han utilizado, por ejemplo, las opiniones consultivas de la Corte para impulsar temas de derechos humanos que ocupan un espacio central en su política exterior, como la protección de sus nacionales que emigran a países centrales. Fue precisamente México aquel que promovió los pronunciamientos del sistema sobre asistencia consular en procesos con pena capital y sobre derechos laborales de inmigrantes en situación irregular, y logró que Estados Unidos se presentara ante la Corte como amicus curiae a defender los postulados de sus propias políticas. Recientemente, el gobierno argentino, de manera articulada con algunas organizaciones sociales, promovió una discusión sobre la legalidad de la práctica de nombramiento de jueces ad hoc por los Estados en los litigios ante la Corte y la potencial afectación del principio de imparcialidad. En los últimos tres años, se han presentado, además, dos demandas interestatales por primera vez desde la entrada en vigencia de la Convención Americana ${ }^{14}$.

También ha crecido la cantidad de funcionarios públicos, jueces, defensores, fiscales y operadores judiciales que han acudido a la CIDH y a la Corte IDH en busca de protección cautelar urgente ante amenazas, intimidaciones o actos de violencia como represalia por el cumplimiento de sus funciones. Estas situaciones rompen el esquema clásico del SIDH como protector de víctimas frente a los abusos de los Estados autoritarios y monolíticos, y pone en evidencia que su escenario de acción es más complejo en la actualidad, de cara a Estados democráticos que expresan ambigüedades, disputas y contradicciones en su interior.

13 Véase Tiscornia, Sofía. Activismo de los derechos humanos y burocracias estatales. El caso Walter Bulacio. Buenos Aires: CELS y Editores del Puerto, 2008.

14 Véase CIDH, Informe 11/2007, caso interestatal 01/06, Nicaragua contra Costa Rica, del 8 de marzo de 2007. Enjuniode2009, la Procuraduríade Ecuadorpresentóunapeticióncontra Colombiaantelasecretaría ejecutiva de laCIDH,en laquealegóviolacionesala Convención AmericanaporlamuertedelseñorFranklin Aisalia, como resultado del operativo militar colombiano de marzo de 2008 contra un campamento de las FARC, ubicado en la localidad ecuatoriana de Angostura.

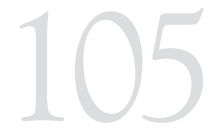

DE LAS

VIOLACIONES

MASIVAS A

LOS PATRONES

ESTRUCTURALES:

NUEVOS

ENFOQUES

Y CLÁSICAS

TENSIONES EN

EL SISTEMA

INTERAMERICANO

DE DERECHOS

HUMANOS 


\section{UNA AGENDA AMPLIADA. LA EXCLUSIÓN Y LA DEGRADACIÓN INSTITUCIONALES}

Este cambio gradual de rol del SIDH en el nuevo escenario político fue acompañado también por un cambio gradual de la agenda de temas tratados por el SIDH. Sin embargo, como vimos, algunos de los viejos temas no han sido superados ni desplazados, como los conflictos de la justicia transicional. La nueva agenda se produce por la incorporación de nuevos temas que conviven con asuntos tradicionales.

En los últimos años, se ha ido consolidando en el SIDH una agenda vinculada a los problemas derivados de la desigualdad y la exclusión social. Ello a partir de la constatación de que, luego de procesos complicados de transición, las democracias latinoamericanas se encuentran seriamente amenazadas por el aumento sostenido de las brechas sociales, y la exclusión de vastos sectores de la población de sus sistemas políticos y de los beneficios del desarrollo, lo que impone límites estructurales al ejercicio de derechos sociales, políticos, culturales y civiles.

Los problemas de desigualdad y exclusión se reflejan en la degradación de algunas prácticas institucionales y en el deficiente funcionamiento de los Estados democráticos, lo que produce nuevas formas de vulneración de los derechos humanos, muchas veces emparentadas con las prácticas de los Estados autoritarios de décadas pasadas. No se trata de Estados que se organizan para violar sistemáticamente derechos, ni que planifican en sus esferas superiores acciones deliberadas para vulnerarlos masivamente, sino de Estados con autoridades electas legítimamente, que no son capaces de revertir e impedir prácticas arbitrarias de sus propios agentes ni de asegurar mecanismos efectivos de responsabilidad por sus actos, como consecuencia del precario funcionamiento de sus sistemas judiciales $^{15}$. Los sectores sociales bajo condiciones estructurales de desigualdad y exclusión son las víctimas principales de este déficit institucional, lo que se refleja en algunos conflictos que ocupan la atención del SIDH: la violencia policial marcada por el sesgo social o racial; el hacinamiento y la tortura en los sistemas carcelarios, cuyas víctimas habituales son los jóvenes de sectores populares; las prácticas generalizadas de violencia doméstica contra las mujeres, toleradas por las autoridades estatales; la privación de la tierra y de la participación política de pueblos y comunidades indígenas; la discriminación de la población afrodescendiente en el acceso a la educación y a la justicia; el abuso de las burocracias contra los inmigrantes indocumentados; los desplazamientos masivos de población rural en contextos de violencia social o política.

De allí que uno de los principales aportes y, al mismo tiempo, de los principales desafíos del SIDH en relación con los problemas regionales originados en la exclusión y la degradación institucional reside en la 
capacidad de guiar con estándares y principios la actuación de los Estados democráticos en las situaciones concretas, tanto la jurisprudencia de los tribunales, a fin de determinar el alcance de los derechos, como los procesos de formulación de políticas públicas; se contribuiría, de tal modo, al fortalecimiento de las garantías institucionales y sociales de esos derechos en los diferentes espacios nacionales.

Frente a este tipo de situaciones, la CIDH y la Corte IDH han procurado examinar no solo casos o conflictos aislados, sino también los contextos sociales e institucionales en que esos casos y conflictos se desarrollan y adquieren sentido. Así como en el tiempo de las dictaduras y el terrorismo de Estado el SIDH había observado la situación de determinadas víctimas, la ejecución y la desaparición de determinadas personas, en función del contexto de violaciones masivas y sistemáticas de derechos humanos, en la actualidad, en numerosas situaciones, ha procurado abrir el foco para enmarcar hechos particulares en patrones estructurales de discriminación y violencia contra grupos o sectores sociales determinados. Para hacerlo, el SIDH se ha basado en una concepción del principio de igualdad que sumariamente intentaremos presentar en lo que sigue. La reinterpretación del principio de igualdad ha permitido al SIDH involucrarse en temáticas sociales a partir de una reinterpretación del alcance de los derechos civiles y políticos establecidos en la Convención Americana.

\section{LOS DERECHOS EN UN ESCENARIO DE DESIGUALDAD ESTRUCTURAL}

Consideramos importante, para ilustrar el cambio de enfoque mencionado, seguir algunas intervenciones del SIDH en asuntos referidos a problemas de igualdad relacionados con diversas formas de violencia, o con asuntos relativos a la participación política y el acceso a la justicia. Estos precedentes marcan una línea jurisprudencial que tiende a una lectura en clave social de numerosos derechos civiles de la Convención Americana, y afirma la existencia de deberes de acción positiva y no solo de obligaciones negativas de los Estados. Esos deberes positivos suelen ser impuestos con mayor intensidad como resultado del reconocimiento de que ciertos sectores sociales viven en condiciones estructurales de desventaja en el acceso o ejercicio de sus derechos básicos.

Si observamos la evolución de la jurisprudencia sobre igualdad en el sistema interamericano, concluiremos que el SIDH demanda a los Estados un rol más activo y menos neutral, como garantes no solo del reconocimiento de los derechos, sino también de la posibilidad real de ejercerlos. En ese sentido, la perspectiva histórica sobre la jurisprudencia del SIDH marca una evolución desde un concepto de igualdad formal, elaborado en la etapa de la transición, hacia un concepto de igualdad sustantivo que se comienza a consolidar en la etapa actual del fin de las

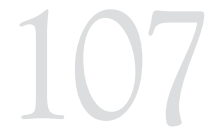

DE LAS

VIOLACIONES

MASIVAS A

LOS PATRONES

ESTRUCTURALES:

NUEVOS

ENFOQUES

Y CLÁSICAS

TENSIONES EN

EL SISTEMA

INTERAMERICANO

DE DERECHOS

HUMANOS 
transiciones a la democracia, cuando la temática de la discriminación estructural se presenta con más fuerza en el tipo de casos y asuntos considerados por el SIDH. Así, se avanza desde una idea de igualdad como no discriminación o como protección de grupos subordinados. Eso significa que se evoluciona desde una noción clásica de igualdad, que apunta a la eliminación de privilegios o de diferencias irrazonables o arbitrarias, que busca generar reglas iguales para todos, y demanda del Estado una suerte de neutralidad o «ceguera» frente a la diferencia. Y se desplaza hacia una noción de igualdad sustantiva, que demanda del Estado un rol activo para generar equilibrios sociales, la protección especial de ciertos grupos que padecen procesos históricos o estructurales de discriminación. Esta última noción presupone un Estado que abandone su neutralidad y que cuente con herramientas de diagnóstico de la situación social para saber qué grupos o sectores deben recibir en un momento histórico determinado medidas urgentes y especiales de protección.

En un informe reciente de la $\mathrm{CIDH}$, se sistematizan algunas decisiones jurisprudenciales del sistema que marcan esta evolución en el concepto de igualdad en relación con los derechos de las mujeres ${ }^{16}$.

Existen algunas consecuencias muy claras a partir de la adopción de una idea de igualdad estructural en el sistema interamericano. La primera es que las acciones de índole afirmativa que adopta el Estado no pueden ser en principio invalidadas bajo una noción de igualdad formal. En todo caso, la impugnación de acciones afirmativas deberá basarse en críticas concretas de su razonabilidad, en función de la situación de los grupos beneficiados en un momento histórico determinado. La segunda consecuencia es que los Estados no solo tienen el deber de no discriminar, sino que, ante ciertas situaciones de desigualdad de índole estructural, tienen la obligación de adoptar acciones afirmativas o positivas de equilibrio para asegurar el ejercicio de los derechos de ciertos grupos subordinados. Una tercera consecuencia es que también pueden violar el principio de igualdad, prácticas o políticas que son en apariencia neutrales, pero que pueden tener un impacto o un efecto discriminatorio sobre ciertos grupos desaventajados. Esto ha sido ya señalado por la Corte, en el caso de Jean y Bosico contra República Dominicana. Una serie de prácticas que en apariencia pueden ser neutrales o pueden no expresar una voluntad deliberada de discriminar a un sector pueden tener como efecto la discriminación de un sector definido, y por ello pueden considerarse violatorias de la regla de igualdad. Estas consecuencias parten de una lectura en clave social del principio de igualdad, ya que implican reconocer cómo ciertas acciones del Estado pueden impactar no en una persona individual, sino en un grupo o en un sector subordinado de la población. Equivale a cambiar el lente y abrir el prisma: 
observar el contexto social y las trayectorias sociales de ciertas personas como parte de un grupo o colectivo sojuzgado o discriminado. De allí que no solo van a ser violatorias del principio de igualdad aquellas normas, prácticas o políticas que deliberadamente excluyan a determinado grupo, sin un argumento razonable o lógico, sino también las que pueden tener efectos o impactos discriminatorios ${ }^{17}$.

$\mathrm{Al}$ mismo tiempo, este concepto de igualdad se refleja en la forma en que el SIDH ha comenzado a releer las obligaciones de los Estados en materia de derechos civiles y políticos en ciertos contextos sociales.

Podemos señalar algunos antecedentes importantes sobre la extensión de los deberes de protección del Estado frente a la actuación de actores no estatales, por ejemplo en materia de violencia contra las mujeres. La $\mathrm{CIDH}$ fijó deberes especiales de protección estatal vinculados con el derecho a la vida y a la integridad física en función de una interpretación del principio de igualdad en línea con la que expusimos. En el caso de María Da Penha Fernández contra Brasil, la $\mathrm{CIDH}$, frente a un patrón estructural de violencia doméstica que afectaba a las mujeres de la ciudad de Fortaleza, en el Estado de Ceará, acompañada por una práctica general de impunidad judicial frente a este tipo de casos criminales, y la negligencia del gobierno local en implementar medidas efectivas de prevención, estableció que el Estado federal había violado el derecho a la integridad física de la víctima y el derecho a la igualdad ante la ley. También estableció que los Estados tienen un deber de acción preventiva diligente para evitar prácticas de violencia contra las mujeres, aun frente a la actuación de actores no estatales, con base no solo en el artículo 7 de la Convención de Belem do Para, sino también en la propia Convención Americana. La responsabilidad del Estado provenía de no haber adoptado medidas preventivas con debida diligencia para evitar que esa forma extendida de violencia existiera y se reprodujera en perjuicio de un grupo o colectivo determinado. $\mathrm{La} \mathrm{CIDH}$ valora fundamentalmente la existencia de un patrón o «pauta sistemática» en la respuesta estatal, que expresa, a su juicio, una suerte de tolerancia pública con la situación de violencia denunciada no solo en perjuicio de la víctima sino con relación a otros casos idénticos o con características comunes. El enfoque, como dijimos, va más allá de la situación particular de la víctima individual, pues se proyecta a la evaluación de la situación de discriminación y subordinación de un grupo social determinado. La situación estructural del grupo de mujeres afectadas por la violencia, por un lado, califica los deberes de prevención del Estado y sus obligaciones reparatorias en el caso particular, pero además justifica el tipo de recomendaciones de

17 En tal sentido, sostuvo la Corte en el caso Jean y Bosico: «La Corte considera que el principio de derecho imperativo de protección igualitaria y efectiva de la ley y no discriminación determina que los Estados, al regular los mecanismos de otorgamiento de la nacionalidad, deben abstenerse de producir regulaciones discriminatoriasoquetenganefectosdiscriminatoriosenlosdiferentesgruposdeunapoblaciónalmomento de ejercer sus derechos. Además, Ios Estados deben combatir las prácticas discriminatorias en todos sus niveles, enespecialen losórganospúblicos,y finalmentedebeadoptarlasmedidasafirmativasnecesarias para asegurar una efectiva igualdad ante la ley de todas las personas».

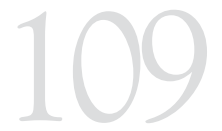

DE LAS

VIOLACIONES

MASIVAS A

LOS PATRONES

ESTRUCTURALES:

NUEVOS

ENFOQUES

Y CLÁSICAS

TENSIONES EN

EL SISTEMA

INTERAMERICANO

DE DERECHOS

HUMANOS 
alcance general que fija la CIDH al Estado y que incluyen, por ejemplo, cambios en las políticas públicas, en la legislación, y en los procedimientos judiciales y administrativos ${ }^{18}$.

La CIDH consideró especialmente el impacto diferenciado sobre ciertos grupos sociales de prácticas extendidas de violencia desarrolladas por agentes estatales o por actores no estatales con la convivencia o tolerancia del Estado. En este orden de ideas, la Comisión, por ejemplo, impuso responsabilidad a Brasil por no haber adoptado medidas para prevenir desalojos forzosos violentos, emprendidos por ejércitos privados de hacendados que eran expresión de un patrón sistemático de violencia rural tolerado por las autoridades estatales, seguido de un patrón de impunidad en las investigaciones criminales de estos hechos. Para eso, la CIDH tuvo especialmente en cuenta la situación de desigualdad estructural en que se encuentra un sector de la población rural en ciertos estados del norte brasileño, y los niveles de tolerancia y connivencia entre sectores poderosos de hacendados, las fuerzas policiales y la justicia estadual ${ }^{19}$. En otro caso, la CIDH responsabilizó a Brasil por un patrón de violencia policial dirigido a jóvenes negros en las favelas de Río de Janeiro, considerando que la ejecución extrajudicial de un joven de este grupo social suponía un hecho representativo de ese patrón, el cual a su vez expresaba un sesgo racista en la actuación de la fuerza pública estadual, con la complicidad de la autoridad federal20. También la CIDH y la Corte IDH consideraron la situación de vulnerabilidad diferenciada frente a la violencia política de ciertos grupos en el marco del conflicto armado interno en Colombia. Impusieron al Estado deberes específicos de protección que implican restricciones en el uso de la propia fuerza estatal y protección especial frente a otros actores no estatales, así como obligaciones especiales de reparación de alcance colectivo, y políticas sociales diferenciadas y culturalmente pertinentes. Estas medidas de protección parten de la obligación de respetar y garantizar ciertos derechos culturales de grupos étnicos, por ejemplo restricciones a determinadas actividades bélicas en resguardo de la integridad de territorios colectivos de pueblos indígenas y comunidades negras colombianas ${ }^{21}$.

Entre los sectores mencionados por el SIDH como grupos discriminados o excluidos que requieren protección especial o tratamiento diferenciado,

18 CIDH, Informe 54/01, «Maria Da Penha Maia Fernández». Brasil, 16 de abril de 2001. Véase también la demanda de la CIDH ante la Corte Interamericana de Derechos Humanos en el caso "Campo Algodonero": Claudia Ivette González, Esmeralda Herrera Monreal y Laura Berenice Ramos Monárrez (casos 12.496, 12.497 y 12.498) contra los Estados Unidos Mexicanos, 4 de noviembre de 2007.

$19 \mathrm{CIDH}$, Informe 25/09, «Sebastiao Camargo Filho». Brasil, 19 de marzo de 2009.

$20 \mathrm{CIDH}$, Informe 26/09, «Wallace de Almeida». Brasil, 20 de marzo de 2009.

21 Pueden consultarse las medidas provisionales de la Corte IDH en el caso del pueblo indígena Kankuamo y delascomunidades afrocolombianas delJiguamiandóyelCurbaradó,entremuchasotras. Véaseademás, para ilustrar el tipo de situaciones colectivas mencionadas en el marco del conflicto armado colombiano, $\mathrm{CIDH}$, «Informe sobre lavisitaal terrenoen relación con las medidas provisionalesordenadas a favor de los miembros de las comunidades constitutitas por elConsejo Comunitario del Jiguamiandóy las familias del Curbaradó,MunicipiodelCarmendelDarien,DepartamentodelChocó,RepúblicadeColombia»,noviembre de 2008. 
se encuentran los pueblos indígenas ${ }^{22}$, la población afrodescendiente ${ }^{23}$ y las mujeres, en relación con el ejercicio de ciertos derechos, tales como la integridad física ${ }^{24}$ y la participación política ${ }^{25}$. También se ha enfatizado la obligación de garantía de los Estados ante la existencia de grupos en situación de vulnerabilidad, como vimos, los niños que viven en la vía pública o en sistemas de internación, los enfermos mentales en reclusión, los inmigrantes indocumentados, la población campesina desplazada de sus territorio o las personas pobres portadoras de VIH/ SIDA, entre otros.

Esta apretada reseña indica que el SIDH no recoge solo una noción formal de igualdad, limitada a exigir criterios de distinción objetivos y razonables, y por lo tanto a prohibir diferencias de trato irrazonables, caprichosas o arbitrarias, sino que avanza hacia un concepto de igualdad material o estructural que parte del reconocimiento de que ciertos sectores de la población están en desventaja en el ejercicio de sus derechos por obstáculos legales o fácticos y requieren, por consiguiente, la adopción de medidas especiales de equiparación. Ello implica la necesidad de trato diferenciado, cuando, debido a las circunstancias que afectan a un grupo desaventajado, la identidad de trato suponga coartar o empeorar el acceso a un servicio o bien o el ejercicio de un derecho. El mismo tiempo obliga a examinar, en un estudio de igualdad, la trayectoria social de la supuesta víctima, el contexto social de aplicación de las normas o las políticas cuestionadas, así como la situación de subordinación o desventaja del grupo social al cual pertenecen los potenciales afectados ${ }^{26}$.

El empleo de la noción de igualdad material conlleva una definición sobre el rol del Estado como garante activo de los derechos, en escenarios

22 SobrelasobligacionespositivasdelosEstadosdegarantizarelejerciciodeciertosderechosciviles,políticos ysociales porlos miembros de lascomunidad indígenas, pueden verse los casos MasacredePlan Sánchez vs. Guatemala, del 29 de abril de 2004; caso Comunidad Moiwana vs. Suriname, del 15 de junio de 2005; y Comunidad Indígena Yakie Axa vs. Paraguay, del 17 de junio de 2005. Recientemente, este principio llevóa laCorteareinterpretar lasobligaciones delEstadoen materiadederechoalavidahastaincorporarundeber de garantizar ciertos mínimos vitales de salud, agua y educación, vinculados con el derechoa la vida digna de una comunidad indígena expulsada de su territorio colectivo, en el caso de Sawhoyamaxa vs Paraguay, 29 de marzo de 2006, y subsiguientes decisiones de supervisión de sentencia.

23 Véase Fry, Peter. “Color e imperio de la ley en Brasil». En J. Méndez, G. O’Donell y P.S. Pinheiro (compiladores). La (in)efectividad de la ley.... Op. cit., pp. 191-212; AriAs, O., Yamada, G. y L. Tejerina. «Ingresos y color en Brasil: una historia compleja». En M. Buvinic, J. Mazza, J. Pungiluppi y R. Deutsch. Inclusión social y desarrollo económicos en América Latina. Washington: BID, 2004, pp. 215-236. Véase el caso Simona André Diniz contra Brasil, Informe 37/02, declarado admisible por la CIDH, en el que se alega incumplimientodeldeberestataldeprotecciónfrenteaconductasdiscriminatoriasdeparticulares,basadas en el color o la raza.

24 Sobrelaobligación deadoptarpolíticasymedidaspositivasparaprevenir,sancionaryerradicarlaviolencia contra las mujeres, puede verse el Informe 54/01, Maria Da Penha Maia Fernandez contra Brasil, 16 de abril de 2001.

25 Véase CIDH, Informe 103/01, «María Merciadri de Moroni». Argentina, 11 de octubre de 2001, sobre cupos en el sistema electoral argentino.

26 Paraunanálisis deestasnociones deigualdaden lafilosofíajurídicayenelDerechoconstitucional, pueden verse, a modo de ejemplo, los siguientes textos: YounG, I.M. «Vida política y diferencia de grupo». En Perspectivas feministas en teoría política. Madrid: Paidós, 1996, pp. 120; consúltese también FerRajoli, L. «Igualdad y diferencia». Derechos y garantías. La ley del más débil. Madrid: Trotta, pp. 73-96; García Añón, J. G. «CurrentProblems of LegalDogmatics inEuropeanRegulation:ThePrincipleofEqualityandthePolicies of Affirmative Action». En M. Barrére Unzueta, M. van Hoecke y F. Ost (editores). Discriminación, Derecho antidiscriminatorio y acción positiva en favor de las mujeres. Madrid: Civitas, 1997, pp.; Fıss, O. «Grupos y la cláusula de igual protección». En R. Gargarella(compilador). Derechoy grupos desaventajados. Barcelona: Gedisa, 1999, pp. 137-167; SABA, R. «(Des)igualdad estructural». En Jorge Amaya (editor). Visiones de la Constitución 1853-2004. Buenos Aires: UCES, 2004, pp. 479-514.

DE LAS

VIOLACIONES

MASIVAS A

LOS PATRONES

ESTRUCTURALES:

NUEVOS

ENFOQUES

Y CLÁSICAS

TENSIONES EN

EL SISTEMA

INTERAMERICANO

DE DERECHOS

HUMANOS 
sociales de desigualdad. Es, además, una herramienta útil para examinar las normas jurídicas, las políticas públicas y las prácticas estatales, tanto su formulación como sus efectos. La imposición de obligaciones positivas tiene consecuencias muy importantes respecto del rol político o promocional del SIDH, pues impone a los Estados el deber de formular políticas para prevenir y reparar violaciones de derechos humanos que afectan a ciertos grupos o sectores postergados.

Asimismo, tiene consecuencias directas en el debate sobre disponibilidad de remedios judiciales, pues es sabido que las obligaciones positivas son más difíciles de exigir en los sistemas de justicia domésticos, en especial cuando se exige comportamientos positivos para resolver conflictos de naturaleza colectiva.

También las obligaciones positivas entran en tensión con las capacidades estatales de los Estados americanos. El SIDH, gradualmente, ha ido sumando a los Estados cada vez más deberes de prevención de violaciones y de protección de derechos frente a la acción de actores no estatales en ciertas circunstancias determinadas. Esta ampliación del marco de obligaciones estatales pone en evidencia la brecha entre las expectativas puestas en los Estados por el SIDH y la realidad signada por la debilidad de las instituciones y la inefectividad de las políticas. Para alcanzar los exigentes estándares del SIDH en materia de obligaciones positivas, se requieren instituciones con capacidad de planificación y gestión de políticas, y con recursos humanos y financieros adecuados. De allí comienza a marcarse con mayor nitidez una creciente brecha entre el discurso normativo y las capacidades reales de satisfacción de las obligaciones impuestas.

Las obligaciones positivas se han fijado también en el SIDH en relación con el ejercicio del derecho a la participación de los pueblos indígenas: entre otras cuestiones, la posibilidad de ejercer su derecho a la consulta previa, libre e informada, respecto a las políticas que pudieran afectar sus territorios comunales, como explotaciones económicas y de recursos naturales, y a dialogar con las instancias del Estado y otros actores sociales ha través de sus propias representaciones políticas ${ }^{27}$. En este tema se observa la directa vinculación entre el ejercicio de derechos culturales y sociales con derechos civiles y políticos, pues la base de la argumentación es el vínculo especial que tienen los pueblos indígenas con sus territorios y recursos, lo que pone en juego no solo intereses económicos, sino la preservación de su identidad cultural y la existencia misma de una cultura ${ }^{28}$. Estos derechos fijados por instrumentos internacionales,

27 Véase AyLwin, José. «Derechos humanos y derechos indígenas en América del Sur: antecedentes, movimientos y desafíos". En Temas de derechos humanos en debate. Santiago de Chile: IDL y Centro de Derechos Humanos Facultad de Derecho de la Universidad de Chile, pp. 153-222.

28 Sobrelosderechoscolectivosrelativosalapreservacióndelasupervivenciadeunaculturaylaneutralidaddel Estado liberal, véaseel clásicoensayo de TAYLOR, Charles. Elmulticulturalismoyla política del reconocimiento. México D.F.: Fondo de Cultura Económica, 1992. También ANAYA, J.S. Los pueblos indígenas en el Derecho internacional. Madrid: Trotta, Universidad Internacional de Andalucía, 2005. 
tales como el Convenio 169 de la OIT, también han recibido reconocimiento con base directa en la Convención Americana, a partir de una relectura en clave social del artículo 21, que consagra el derecho de propiedad. En una serie de decisiones, la Corte Interamericana ha establecido la obligación de los Estados de disponer mecanismos adecuados para la participación, la producción de información de impactos social y ambiental, y la consulta dirigida hacia la búsqueda de consentimiento de los pueblos indígenas en aquellas decisiones que pueden afectar el uso de sus recursos naturales o que pueden alterar sus territorios. En este sentido, se trata del reconocimiento de facultades de participación diferenciada en decisiones de políticas públicas del Estado nacional, pero que, al mismo tiempo, definen más que un derecho procedimental y alcanzan el reconocimiento de un «derecho especial del grupo» a preservar un ámbito de autogobierno o de autonomía en esas cuestiones ${ }^{29}$. Si bien la jurisprudencia del SIDH ha establecido que se no se trata de un poder de veto en favor de los pueblos indígenas, se trata, sin duda, de uno de los campos más conflictivos dentro de los temas que aborda en la actualidad el SIDH, pues aquí se observa con mayor nitidez la tensión entre el reconocimiento de un derecho diferenciado en favor de un colectivo y el interés público involucrado en ciertas estrategias de desarrollo económico de los gobiernos nacionales.

En una decisión reciente, la Corte Interamericana de Derechos Humanos estableció la obligación de los Estados de adoptar medidas positivas para garantizar que pueblos y comunidades indígenas puedan participar, en condiciones de igualdad, en la toma de decisiones sobre asuntos y políticas que inciden o pueden incidir en sus derechos y en el desarrollo de dichas comunidades, de forma tal que puedan integrarse a las instituciones y órganos estatales, y participar de manera directa y proporcional a sus poblaciones en la dirección de los asuntos públicos, así como hacerlo desde sus propias instituciones políticas y de acuerdo con sus valores, usos, costumbres y formas de organización. La Corte, en la sentencia dictada en el caso Yatama ${ }^{30}$, consideró que la legislación nicaragüense sobre monopolio de partidos políticos y las decisiones de los órganos electorales del Estado habían limitado irrazonablemente la posibilidad de participación en un proceso electoral de una organización política

29 Corte IDH, caso de la Comunidad Mayagna (Sumo)Awas Tingni, sentencia del 31 de agosto de 2001, y también los casos Plan Sánchez; Moiwanay Yakie Axa, antes citados. Reciente, Corte IDH, caso Pueblo de Saramaka c. Suriname, sentencia del 28 de noviembre de 2007.

30 Corte IDH, caso Yatama contra Nicaragua, 23 de junio de 2005. En esta sentencia, la Corte comienza a definir el alcance del derecho a la participación política, consagrado en el artículo 23 de la Convención Americana,yconsideraquecomprendeademásdelaparticipaciónenprocesoselectoralesformalestambién laparticipaciónenotrosmecanismos dediscusiónyfiscalización depolíticaspúblicas.Tambiénseprocura avanzar en la sentencia en mayores precisiones sobre el alcance de la obligación estatal de garantizar este derechode participación respectodesectores sociales excluidos oqueseencuentran en situación de desventaja en el ejercicio de este derecho. Para ello, el tribunal vincula el derecho a la igualdad, entendido comoigualdadnosoloformalsinosustantiva,conelderechodeasociaciónydeparticipación política. Véase en tal sentido el voto concurrente del juez Diego García Sayán. Para entender mejor el sentido que la propia Corte IDH le da a su decisión en Yatama, se sugiere leer también cómo lo diferencia de un caso posterior sobreexclusióndecandidaturas independientes, alconsiderarespecialmenteen Yatamalaexistenciadeun gruposubordinadoconcaracterísticas deidentidadculturaldiferenciadas. VéaseCorteIDH,casoCastañeda Gutman Jorge vs. Estados Unidos Mexicanos, 6 de agosto de 2008, párrafo 172.

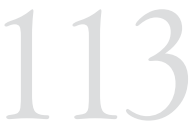

DE LAS

VIOLACIONES

MASIVAS A

LOS PATRONES

ESTRUCTURALES:

NUEVOS

ENFOQUES

Y CLÁSICAS

TENSIONES EN

EL SISTEMA

INTERAMERICANO

DE DERECHOS

HUMANOS 
representativa de las comunidades indígenas de la costa atlántica del país. Este caso, también en nuestra opinión, expresa la afirmación del principio de igualdad estructural, pues la Corte IDH obliga al Estado a flexibilizar la aplicación de las normas electorales de alcance general para adecuarlas a las formas de organización política que expresan la identidad cultural de un grupo. En definitiva, lo que la Corte reconoce es un «derecho especial o diferenciado a favor de un grupo» ${ }^{31}$ que fija ciertas «protecciones externas» al grupo minoritario, consideradas indispensables para la preservación de su autonomía; pero también reconoce su participación en las estructuras del propio Estado nacional.

Se han fijado, en el SIDH, fuertes obligaciones positivas en relación con el derecho de acceso a la justicia que representan otra proyección, en este campo, de la referida noción de igualdad sustantiva. El SIDH ha fijado estándares bastante precisos sobre el derecho a contar con recursos judiciales y de otra índole que resulten idóneos y efectivos para demandar por la vulneración de los derechos fundamentales. En tal sentido, la obligación del Estado no es solo negativa, de no impedir el acceso a esos recursos, sino fundamentalmente positiva, de organizar el aparato institucional de modo que todos, y en especial aquellos que se encuentran en situación de pobreza o exclusión, puedan acceder a esos recursos. Para ello deberá remover los obstáculos sociales o económicos que obstaculizan o limitan la posibilidad de acceso a la justicia, pero además el Estado deberá organizar un servicio público de asistencia jurídica gratuita, y mecanismos para aliviar gastos y costas de los procesos para hacerlos asequibles, por ejemplo al establecer sistemas para eximir gastos. ${ }^{32}$ Las políticas que apuntan a garantizar servicios jurídicos a personas carentes de recursos actúan como mecanismos para compensar situaciones de desigualdad material que afectan la defensa eficaz de los propios intereses y, por ello, son políticas judiciales que se emparentan con políticas sociales. El SIDH ha fijado la existencia de un deber estatal de organizar estos servicios para compensar situaciones de desigualdad real y garantizar igualdad de armas en un proceso judicial. Ha determinado, además, algunas obligaciones concretas de debido proceso que se aplican en relación con los procedimientos judiciales de índole social, como los juicios laborales y previsionales, y las acciones de amparo y

31 VéasealrespectoКумціска,W. «Nacionalismominoritariodentrodelasdemocraciasliberales». EnS.García y S. Lukes. Ciudadanía: justicia social, identidad y participación. Madrid: Siglo XXI Editores, 1999. También Kyмıicka, W. Ciudadanía multicultural. Barcelona: Paidós, 1996.

$32 \mathrm{CIDH}$, Opinión Consultiva OC-11/90 del 10 de agosto de 1990, «Excepciones al agotamiento de los recursos internos (artículos 46.1,46.2.a y 46.2.b CA)». Inspirándose en el caso Airey, la Corte sostuvo que: «[...] la circunstancias de un procedimiento particular, su significación, su carácter y su contexto en un sistema legal particular, son factores que fundamentan la determinación de si la representación legal es o no necesaria para el debido proceso" (párrafo 28). También se refirió expresamente a la obligación estatal de garantizar servicios jurídicos gratuitos a las personas sin recursos cuando resulte indispensable para garantizar acceso efectivo y igualitario a la justicia en la Opinión Consultiva 18/03, Condición Jurídica y Derechos de los Migrantes Indocumentados. En este documento, sostuvo la Corte: «Se vulnera el derecho a las garantías y a la protección judicial por varios motivos: por el riesgo de la persona cuando acude a las instanciasadministrativasojudiciales deserdeportada,expulsadaoprivadadesulibertad,y porlanegativa de la prestación de un servicio público gratuito de defensa legal a su favor, lo cual impide que se hagan valer los derechos en juicio. Al respecto, el Estado debe garantizar que el acceso a la justicia sea no solo formal sino real». 
desalojo. Recientemente, ha fijado algunos indicadores para evaluar el cumplimiento de estas obligaciones por los Estados ${ }^{33}$.

Esta base de obligaciones positivas impuestas a los Estados, vinculada al reconocimiento de un escenario de desigualdad que caracteriza la realidad americana, sirve en ocasiones como marco para el examen de las políticas públicas en los informes temáticos y de país, como fuera mencionado arriba, y es una herramienta central para el trabajo promocional de los órganos del SIDH.

\section{OBJECIONES A LA AMPLIACIÓN DE LA AGENDA Y LOS MÁRGENES DE LA PROTECCIÓN INTERNACIONAL}

Existe, en el ámbito de la OEA, un debate político sobre la ampliación de la agenda. Un tipo de críticas a la ampliación de la agenda no se relaciona con el rol del SIDH en particular, sino con una discusión más amplia sobre qué se entiende por derechos humanos y qué tipo de derechos deben ser resguardados por el Estado de modo prioritario. Las posiciones liberales clásicas expuestas en la OEA por algunos Estados critican la ampliación de la agenda del SIDH hacia temas de igualdad sustantiva y derechos colectivos, la extensión de obligaciones positivas $y$, en especial, el tratamiento, aunque sea indirecto, de derechos económicos, culturales y sociales. Desde estas posturas conservadoras, el concepto de derechos humanos debería limitarse a los derechos civiles entendidos como derechos de individuos y no de grupos, y como fuente de obligaciones esencialmente negativas de respeto o no injerencia de los Estados. Se busca así evitar que, por la vía del reconocimiento de deberes positivos, se avance en el tratamiento en este espacio de cuestiones relativas a políticas sociales o distributivas, y se pierda el foco central en el resguardo de las libertades públicas. En sus versiones más pragmáticas, estas posturas no necesariamente cuestionan algunos desarrollos jurisprudenciales del SIDH que mencionamos en el artículo, sino que previenen sobre las consecuencias de que se profundice ese camino en el futuro y se pierda capacidad operativa para el seguimiento de los demás asuntos clásicos de derechos civiles que todavía están presentes como problemas regionales y que deberían merecer tratamiento prioritario. Este enfoque sobre la noción de derechos humanos suele contrastar, en algunas discusiones en el seno de la OEA, con las posturas de otros gobiernos que, con variados matices ideológicos, defienden la existencia de un vínculo de interdependencia entre los derechos civiles y sociales o que, directamente en el polo opuesto, plantean que hay que priorizar la defensa de los derechos sociales por sobre los derechos civiles.

DE LAS

VIOLACIONES

MASIVAS A

LOS PATRONES

ESTRUCTURALES:

NUEVOS

ENFOQUES

Y CLÁSICAS

TENSIONES EN

EL SISTEMA

INTERAMERICANO

DE DERECHOS

HUMANOS 
Pero el eje de la discusión particular sobre la ampliación de la agenda del SIDH en los órganos políticos de la OEA no pasa, en nuestra opinión, por el alcance de la noción de derechos humanos ni sobre las prioridades entre derechos civiles y sociales. Apunta, por el contrario, a la definición del grado de intervención de la instancia internacional sobre los márgenes de autonomía de los Estados. La ampliación de la agenda implica naturalmente una extensión de los asuntos sobre los cuales el SIDH ejercerá supervisión y eventualmente tomará decisiones que pueden impactar a nivel interno de los países. La discusión es relevante, pues se vincula en definitiva con la definición del sentido de un sistema internacional de protección de derechos humanos en el actual escenario político regional.

La mayoría de los países de América Latina aprobaron tratados de derechos humanos y se incorporaron al SIDH en la etapa de las transiciones a la democracia, con finalidades diferentes, pero en muchos casos como una suerte de antídoto para aventar el riesgo de regresiones autoritarias, y ataron así sus sistemas políticos y legales al «mástil» de la protección internacional ${ }^{34}$. Abrir los asuntos de derechos humanos al escrutinio internacional fue una decisión funcional a los procesos de consolidación de la institucionalidad durante las transiciones, pues contribuyó a ampliar las garantías de los derechos fundamentales en un sistema político acotado por actores militares con poderes de veto y presiones autoritarias aún poderosas ${ }^{35}$.

Muchos líderes y gobiernos entienden que la actual coyuntura regional exige replantear el alcance o el grado de intervención del sistema interamericano en asuntos locales que, a su entender, podrían ser dirimidos por el juego institucional del propio Estado, en un marco de democracias constitucionales.

Así, desde este punto de partida, se construyen argumentos que tienen diferentes tonos. Los argumentos más moderados, con rasgos «comunitaristas», apuntan a preservar un espacio de autogobierno para la decisión de ciertos asuntos sensibles y complejos que deberían ser resueltos en el espacio más cercano de la comunidad política nacional ${ }^{36}$. Estos

34 JohnElsterplanteóestametáforapara referirse al actoconstituyenteen su libro Ulisesylassirenas:estudios sobre racionalidad e irracionalidad, de 1979.

35 Paraalgunosautores,comoAndrewMoravcsik,lasdemocraciasrecientementeestablecidasypotencialmente inestablessonlasqueencuentranmayorjustificaciónalasuscripcióndetratadosdederechoshumanosyala inserciónensistemasinternacionalescomomecanismosparalaconsolidacióndelademocracia. Larenuncia aciertosniveles deautodeterminaciónqueimplicalafirmadeestostratadosylaaceptación dejurisdicciones internacionales tiene un costo porla limitación de la discrecionalidad gubernamentaly delsistemapolítico local,quejuegaenunbalanceconlasventajas delareduccióndelaincertidumbrepolítica. MorAvcsık, A. «The Origins of Human Rights Regimes: Democratic Delegation in Postwar Europe». InternacionalOrganizations, primavera de 2000, pp. 217-249. En igual sentido, puede verse KAHN, Paul W. «EI Derecho internacional y la comunidad». En Estado de derecho y democracia. Un debate sobre e/ rule of law. SELA 2000 - Seminario en Latinoamérica de Teoría Constitucional y Política. Buenos Aires: Editores del Puerto, 2001.

36 En este punto, solo apuntamos a contestar argumentos corrientes de algunos gobiernos en la OEA y no a dar cuenta del debate más profundo que plantean las posiciones «comunitaristas» a la existencia y el funcionamiento de los sistemas internacionales de derechos humanos, y quecomose sabenoselimitaala definición deuncampodecuestionesquedeberían ser resueltas por lacomunidadespolíticas locales, sino tambiénalcuestionamientodelos «déficitdedeliberacióndemocrática» quepresentanalgunossistemasde justiciainternacional.Sinperjuiciodeello, abordamosindirectamenteestosasuntosalreferirnosalprincipio 
argumentos se suelen presentar muchas veces no como cuestionamientos directos a la competencia de los órganos, sino como argumentos estratégicos que procuran proteger la integridad del propio sistema de protección; evitan así que abra frentes de conflicto innecesarios con los gobiernos y malverse la noción de derechos humanos como una «carta de triunfo» para usar estratégicamente en las situaciones extremas. Se plantea que una extensión de la noción de derechos humanos en el sistema interamericano podría debilitar los acuerdos políticos que lo sostienen.

Estas posturas, con fundamentos diversos, resultan más o menos refractarias a la injerencia de los órganos internacionales de derechos humanos en ciertos temas sociales e institucionales. Critican concretamente la extensión del concepto de debido proceso que ha permitido al SIDH intervenir en un amplio abanico de temas judiciales que incluyen procesos laborales, de seguridad social, disciplinarios, administrativos y casos de remoción de magistrados de altas cortes de justicia. Cuestionan además que el SIDH se entrometa en asuntos electorales, aun cuando se trate de cuestiones vinculadas con la vigencia de derechos políticos reconocidos por el artículo 23 de la Convención. También se oponen a la protección de derechos colectivos que entran en conflicto con las estrategias de desarrollo económico de los gobiernos, tales como la protección de territorios indígenas y el derecho de consulta. Algunos gobiernos que defienden el reconocimiento de estos derechos colectivos como asuntos de derechos humanos relevantes consideran que se trata de cuestiones que deberían ser discutidas y dirimidas esencialmente en el plano político doméstico. Conviene analizar brevemente estos argumentos con algunas aclaraciones previas.

En primer lugar, en relación con el argumento que procura preservar al SIDH de nuevos «frentes de conflicto» con los gobiernos, es importante señalar que las principales tensiones políticas que provoca la actuación de la CIDH y la Corte, y que por su complejidad no vamos a examinar en este artículo ${ }^{37}$, no se producen por sus intervenciones en temas sociales o institucionales «novedosos», sino que obedecen a la reacción de algunos gobiernos al escrutinio del SIDH en temas «clásicos» de violación de derechos civiles que lamentablemente siguen teniendo vigencia: ejecuciones extrajudiciales, paramilitarismo, militarización y justicia penal militar, limitaciones de la disidencia política y libertad de prensa, entre otras cuestiones. De allí que es bueno aclarar que no son precisamente los temas de igualdad y derechos sociales los que motivan las reacciones más airadas de los Estados, aunque por supuesto también conllevan aspectos polémicos.

de subsidiariedad en este título, y a problemas institucionales de transparencia y rendición de cuentas del propioSIDH, yalalcancedelos remedios judiciales internacionales, en lapartefinal delartículo(punto VIII). 37 Elcuestionamientoalaampliacióndelaagendanoesporsupuestoelúnicotemadecríticasdelosgobiernos a la CIDH y a la Corte IDH. Las cuestiones son muchas otras: en su mayoría tienen que ver con aspectos procedimentales tanto del sistema de casos como de los procesos de elaboración de informes yfijación de audiencias, que no vamos a considerar aquí.

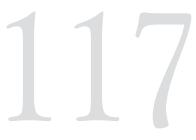

DE LAS

VIOLACIONES

MASIVAS A

LOS PATRONES

ESTRUCTURALES:

NUEVOS

ENFOQUES

Y CLÁSICAS

TENSIONES EN

EL SISTEMA

INTERAMERICANO

DE DERECHOS

HUMANOS 
En segundo lugar, corresponde decir que algunas discusiones sobre la limitación de la autonomía política suelen partir de una visión simple o esquemática del proceso de creación de normas internacionales y de su aplicación doméstica. Por un lado, restan importancia a la participación de actores sociales o institucionales locales en la creación de normas y estándares internacionales de derechos humanos. Por otro lado, consideran la aplicación doméstica como si fuera una imposición externa al sistema político y jurídico local, sin considerar que esa incorporación solo es posible por la activa participación de actores sociales, políticos y judiciales relevantes, así como por la construcción gradual de consensos en los diversos ámbitos institucionales. De allí que suelen marcarse líneas divisorias nítidas entre la esfera internacional y la doméstica, cuando la dinámica de actuación de los mecanismos internacionales evidencia que esa frontera es mucho más borrosa y que existe una constante articulación y relación entre la esfera local e internacional, tanto en la creación como en la interpretación y en la aplicación de normas de derechos humanos. Así, actores sociales y políticos locales relevantes suelen participar de los procesos de creación de normas en la esfera internacional, tanto de la aprobación y ratificación de tratados como en las decisiones de los órganos internacionales que definen su contenido por vía de interpretación y su aplicación en casos o situaciones particulares. Al mismo tiempo, esas normas internacionales se incorporan al ámbito nacional por la acción de los congresos, los gobiernos y los sistemas de justicia, y también con la activa participación de organizaciones sociales que promueven, demandan y coordinan esa aplicación nacional con las diversas instancias del Estado. La aplicación de normas internacionales en el ámbito nacional no es un acto mecánico, sino un proceso que involucra también diferentes tipos de participación y deliberación democrática, e incluso un amplio margen para la relectura o reinterpretación de los principios y normas internacionales en función de cada contexto naciona $^{38}$. En relación con el SIDH, como vimos en los puntos II y III de este artículo, en la actualidad, a diferencia del período de las dictaduras, su intervención en ciertos asuntos domésticos puede obedecer a relaciones de coordinación o articulación con diversos actores locales, públicos y sociales que participan tanto de la formulación de las demandas ante la instancia internacional como en los procesos de implementación de sus decisiones particulares o de sus estándares generales en el ámbito interno ${ }^{39}$. De allí que siempre resultara difícil conceptualizar su intervención

38 Martín Böhmer, contestando críticas formuladas a la ausencia de validación democrática del Derecho internacional,señalaqueelmomentodevalidaciónnopuedequedarlimitadoaldelacelebracióndetratados o la aprobación de normas internacionales, sino que comprende también el proceso de interpretación y aplicación porlosórganosjudicialesy políticoslocales. Así,lasnormas internacionalesnoson un producto acabado y unívoco, sino que están abiertas a diferentes lecturas del plano nacional y autorizan, en ese procesodelectura,laincorporacióndenivelesdedeliberación,asícomolaconsideracióndelcontextosocial y político de cada comunidad. Véase BöHMER, M. «Prestamos y adquisiciones. La utilización del Derecho extranjerocomounaestrategiadecreación deautoridaddemocráticayconstitucional». En<www.law.yale. edu/documents/pdf/sela/MartinBöhmer_Spanish.pdf $>$.

39 Enesteorden de ideas, al tratar de responder la pregunta acerca de por qué los Estados deberían obedecer el Derecho internacional, Harold Koh propone considerar que la asunción de las obligaciones jurídicas internacionalesesfrutodeun «procesojurídicotransnacional»queconsisteenunconjuntodesubprocesos complejos y de variadas dimensiones que incluyen la articulación, la interpretación y la incorporación del 
como una limitación del margen de autonomía de los procesos políticos nacionales. El juego de la intervención internacional en este escenario es variado y complejo, pero por lo general cuenta con el apoyo de actores locales fuertes que activan la respuesta internacional y potencian luego sus efectos domésticos. En ocasiones, la CIDH se apoya en la sociedad civil para fiscalizar al gobierno a la manera clásica ${ }^{40}$, pero también puede actuar de manera coordinada con los gobiernos federales para lograr la implementación de medidas o políticas a nivel de los Estados locales o de provincias ${ }^{41}$. En ocasiones se apoya en decisiones precedentes de los tribunales para tener pautas de seguimiento de acciones del congreso o del gobierno ${ }^{42}$; o los gobiernos o los congresos piden su intervención para contribuir a alcanzar consensos con otros poderes como la judicatura ${ }^{43}$ o para acompañar la implementación de medidas resistidas por actores sociales o políticos locales ${ }^{44}$. Vimos también cómo, en ciertos casos y en especial en procesos de negociación o de «solución amistosa», el juego de alianzas es aun más complejo: incluso agencias públicas son usuarias del SIDH, a veces en alianza con organizaciones sociales, y procuran activar el escrutinio internacional sobre determinadas cuestiones.

Con esta breve reseña no pretendemos negar la importancia de preservar la autonomía política de los Estados para decidir sobre determinadas materias, sino simplemente relativizar ciertas interpretaciones esquemáticas acerca de cómo funciona en la realidad un sistema de justicia internacional y cómo se relaciona con los procesos políticos nacionales.

Respecto de los cuestionamientos concretos ante la ampliación de la agenda del SIDH, es oportuno señalar que esta ampliación no ha sido fruto de una decisión artificial o arbitraria, sino el resultado de

Derechointernacionalenelámbitolocal, através demecanismospolíticos, socialesyjurídicos. KоH, Harold H. «Transnational Legal Process». Nebraska LawReview, 1996;y «Why do Nations Obey International Law? Yale Law Journal, 1997; "International Law as Part of Our Law», American Journal of International Law, volumen 43 , número 98.9

40 Porejemplo,cuandorecibeinformaciónsobresituacionesparticularesparaelaborarsusinformes, yaseaa través de audiencias en su sede o durante visitas al país.

41 Esta situación se observa, por ejemplo, en algunos casos sobre superpoblación y violencia en cárceles estaduales en Brasil y Argentina, en los cuales la intervención del SIDH ha motivado distintas formas de intervención de la autoridad federal en los sistemas penitenciarios locales. También, por ejemplo, en un acuerdorecientedesoluciónamistosacelebradoconelgobiernofederalen México,quemotivólaadopción por estados locales de un protocolo sobre abortos no punibles.

42 Por ejemplo, en Colombia ha utilizado como marco para seguir situaciones de derechos humanos las decisionessobredesplazadosinternosdelaCorteConstitucional.Ensentidoinverso, algunasdecisionesde la Corte Constitucional, porejemplo sobre mujeres desplazadasenel marco del conflictocolombiano, han impuestoobligacionesdeprestaciónalEstadoyhanconsiderandocomofundamento,entreotrosestándares constitucionales, decisionesyjurisprudenciadelSistemalnteramericanodeDerechos Humanos. Inclusouna reciente decisión de la Corte Constitucional invita a la CIDH a integrarse a un sistema de monitoreo del cumplimiento de la sentencia doméstica.

43 Haocurridoestasituación, porejemplo,en losacuerdos desoluciónamistosasobrelaamnistíaperuanaen el caso Barrios Altos, en el que el gobierno peruano, los peticionarios y la CIDH pidieron a la Corte IDH que definieralosestándaressobrecompatibilidad delas leyesdeamnistíadegravesviolacionesalos derechos humanosconlaConvención Americana, afindebrindarunmarcojurídicoalostribunalesnacionalesparaque procedieran a la reapertura de los casos judiciales cerrados en virtud de esas leyes. También, por ejemplo, losacuerdos desolución amistosa sobrelatramitación decausasjudicialessobreelderechoalaverdaden Argentina,celebradosporpeticionariosyelgobierno,contribuyeronacomprometerlaactuacióndelsistema judicial local en su implementación.

44 Véase,porejemplo,laintervencióndelaCIDHenlosconflictosrelacionadosconlasituacióndesemiesclavitud de familias indígenas guaraníes en haciendas del Chaco boliviano y las trabas a la implementación de la legislaciónsobrereformaagrariaenlosdepartamentosdelorienteboliviano. Véaseelcomunicadodeprensa 26/08 del 13 de junio de 2008.

DE LAS

VIOLACIONES

MASIVAS A

LOS PATRONES

ESTRUCTURALES:

NUEVOS

ENFOQUES

Y CLÁSICAS

TENSIONES EN

EL SISTEMA

INTERAMERICANO

DE DERECHOS

HUMANOS 
un cambio gradual de prioridades, expresado en la variación de las demandas de ciudadanía en los propios países de la región. Esas demandas, por lo demás, no son sofisticadas o extravagantes, sino que apuntan a derechos que fueron ya reconocidos por la OEA desde 1948, como el acceso a los tribunales y los derechos políticos. Dando vuelta al argumento que procura preservar la integridad del SIDH, podríamos preguntarnos cuál sería su relevancia si no hubiera evolucionado en función de estas dinámicas sociales y hubiese quedado atado a los temas clásicos de derechos humanos, sin reaccionar frente a las situaciones planteadas por peticionarios y víctimas. ¿Quiénes serían hoy sus usuarios y qué grado de legitimidad tendría el SIDH en nuestras sociedades? En ese sentido, en relación con el argumento de la preservación del sistema, es bueno señalar que este no se sostiene exclusivamente en el compromiso político de los gobiernos. Una base de apoyo fundamental es la legitimidad alcanzada precisamente en un amplio espectro de organizaciones, comunidades y movimientos sociales, y en sus propias redes de alianzas y articulaciones en los países del norte.

Existen, de todos modos, algunos aspectos relevantes a considerar en esta línea de planteos «comunitaristas». El SIDH tiene que dar cuenta del cambio del escenario político regional y no puede intervenir en los procesos nacionales de la manera en que lo hizo para presionar las dictaduras. Este cambio de enfoque no consiste en imponerse restricciones o tabicarse de cara a ciertos temas que están cubiertos por el elenco de derechos humanos reconocidos expresamente en la Convención y los demás tratados e instrumentos interamericanos. Por el contrario, el SIDH se limita cuando fija de forma seria y consecuente su campo de actuación en función de un rol subsidiario de los mecanismos de protección domésticos, de modo que preserva márgenes de acción y prioridad en la intervención a los sistemas de justicia nacionales y admite que existen aspectos sensibles en ciertos conflictos que, por su complejidad, resultan mejor analizados, comprendidos y resueltos en la esfera local.

De ese modo, el resguardo de la autonomía de los Estados se expresa en el alcance de la interpretación que hace el SIDH de algunas reglas procesales que definen su grado de intervención. Se trata, por ejemplo, de la regla que exige el «agotamiento previo» de los recursos y remedios disponibles en el ámbito interno del país para remediar la situación, así como de aquella de la «cuarta instancia», en virtud de la cual el SIDH se inhibe de revisar el acierto o el error de las decisiones de los tribunales nacionales en materias no regidas directamente por la Convención, siempre que se respeten las garantías de procedimiento.

La primera regla del «agotamiento previo de recursos internos», si bien posee naturaleza procesal, resulta un factor clave para entender la dinámica de funcionamiento de todo el sistema interamericano y en especial de su función subsidiaria. Al obligar a presentar y agotar el sistema de acciones y recursos organizado por el sistema judicial del Estado nacional, 
se brinda a cada Estado la posibilidad de solucionar el conflicto y remediar las violaciones antes de que el asunto sea examinado en la esfera internacional. El alcance que se le brinda a esta regla en la jurisprudencia de los órganos del SIDH marca en definitiva los grados de intervención que está dispuesto a ejercer en las diferencias situaciones, sobre la base de la mayor o menor idoneidad y eficacia del sistema judicial nacional.

La segunda regla, denominada de la «cuarta instancia», funciona como una suerte de margen de deferencia a los sistemas judiciales nacionales, pues les reconoce un amplio margen de autonomía para actuar en la interpretación de las normas locales y la decisión de los casos particulares, bajo la condición exclusiva de que respeten las garantías procesales establecidas en la Convención ${ }^{45}$.

También el SIDH ha dado cuenta del nuevo escenario de democracias constitucionales en la región, y ha reconocido márgenes de deferencia a los Estados nacionales en la definición de ciertos asuntos sensibles, como el diseño de los sistemas electorales en función de cada contexto social e histórico, y siempre que se respete el ejercicio igualitario de los derechos políticos ${ }^{46}$.

En algunos casos, además, la CIDH ha considerado, especialmente en su examen de la aplicación de la Convención en casos particulares, los argumentos desarrollados por los tribunales superiores de los Estados que han aplicado la misma Convención o analizado los mismos asuntos con sus propios parámetros constitucionales. No se trata del reconocimiento de márgenes de deferencia en sentido estricto, sino de la consideración especial de ciertas decisiones de tribunales internos como punto de apoyo o como una base de argumentación que particularmente es tenida en cuenta por la CIDH al realizar su propio examen del caso. Este tipo de argumentación sostenida en decisiones de tribunales locales se ha considerado, por ejemplo, en análisis sobre la racionabilidad de leyes internas que impusieron restricciones de derechos fundamentales. Lo ha hecho, por ejemplo, considerando razonables argumentos de tribunales locales que determinaron la proporcionalidad de condenas de daños y perjuicios por difamación, a fin de determinar si se había violado la libertad de prensa $^{47}$. También lo hizo al examinar una decisión de un tribunal nacional acerca de la racionabilidad de una reforma del sistema de seguridad social, a fin de determinar si esa reforma cumplía con parámetros de

45 Véase la doctrina expuesta por la CIDH en sus informes de inadmisibilidad más recientes, incluso para inhibirse de revisar condenas penales alegadas como injustas, ante la imposibilidad de reemplazar a los tribunales nacionales en la valoración de la prueba. Por ejemplo, CIDH, Informe 87/2007, Luis de Jesús MaldonadoManzanilla. México,17deoctubrede2007.Porsupuesto,ellímiteentrerevisión decontenidode las sentencias, o de la evaluación de la prueba del juicio, y el estudio de la vulneración de ciertas garantías procesales fijadas por la Convención es a veces borroso y requiere afinar los estándares técnicos.

46 Véaseeldebatesobreobligacionespositivas delEstadoenmateriaelectoralyelmargendedeferenciapara diseñar sistemas electorales y de partidos políticos. CIDH, Informe 113/06, Fondo y Admisibilidad, Jorge Castañeda Gutman. México, 26 de octubre de 2006, párrafos 173 y 174. Véase, además, la demanda de la CIDH ante la Corte IDH, Jorge Castañeda Gutman. Caso 12.535 contra los Estados Unidos Mexicanos. También Corte IDH, caso Castañeda Gutman, Jorge vs. Estados Unidos Mexicanos, 6 de agosto de 2008, párrafos 162-166 y 193.

47 Véase CIDH, Informe 23/08, Fondo, caso Dudley Stokes. Jamaica, 14 de marzo de 2008. 
proporcionalidad y progresividad, y por lo tanto si existían restricciones legítimas de derechos sociales ${ }^{48}$.

Como vimos, la aplicación con mayor rigurosidad de estos institutos procesales y las materias en las cuales el SIDH ha reconocido márgenes de apreciación a las autoridades nacionales expresan que el SIDH toma en cuenta el nuevo escenario de democracias constitucionales en el continente y procura un equilibrio entre autonomía y protección internacional. Por un lado, restringe su intervención con respecto a ciertos asuntos sensibles que considera que deben ser resueltos en el ámbito del Estado. Por otro lado, se fija una regla general que conduce a modular la intervención en función del grado de desarrollo de la institucionalidad en cada Estado. Así, cuanto mayor es el grado de desarrollo de la institucionalidad doméstica, mayor es el margen de autonomía que se reconoce al Estado y menor el alcance de la intervención del sistema. El SIDH interviene exclusivamente cuando el Estado no logra asegurar un mecanismo idóneo y efectivo para garantizar los derechos en el ámbito interno. Lo cierto es que, precisamente, uno de los mayores déficits de las democracias latinoamericanas reside en la ineficacia e inequidad de sus sistemas judiciales, que no logran remediar la afectación de derechos fundamentales y se vuelven ellos mismos un factor de vulneración de derechos (como veremos en el punto VIII).

El argumento de autonomía y el principio de subsidiariedad tienen además connotaciones especiales cuando nos referimos a conflictos de vulneración de derechos por patrones de desigualdad o exclusión. Como vimos, esta cuestión no se limita a la afectación de derechos económicos, culturales o sociales, sino que por lo general se presenta ante el $\mathrm{SIDH}$ como casos de vulneración de derechos civiles y políticos. No son formalmente planteos de nuevos derechos, sino otra dimensión de problemas clásicos de violencia y discriminación. Es verdad que estos casos imponen cargas fuertes a los Estados, pues obligan, como dijimos, a acciones positivas de alcance colectivo y extienden la responsabilidad indirecta del Estado por conductas de actores no estatales. Pero el aumento de las cargas estatales se relaciona con la magnitud de los desequilibrios sociales que se procura reparar. Aquí el SIDH está jugando un rol indispensable, que tiene una fuerte relación con el rol que jugó durante el terrorismo de Estado en América Latina y en el cual el carácter subsidiario de su intervención debe evaluarse cuidadosamente en función de las restricciones de la capacidad de acción colectiva y de autodefensa de derechos de los grupos afectados. Esa función del SIDH consiste precisamente en ampliar la voz de los sectores más débiles de la población, aquellos que están fuera del sistema de representación social o política, que no logran acceder con fuerza a la esfera pública, que no alcanzan los sistemas de protección social y judicial del Estado, y que 
sienten que las reglas del juego político en los Estados nacionales no ofrece salidas y conducen a la reproducción de las injusticias sociales. En ese sentido, la subordinación estructural de ciertos sectores sociales presenta características similares a la asfixia política por el cierre de la esfera pública por los Estados autoritarios. Se trata de esas situaciones extremas en las cuales el espacio político del Estado nacional funciona como una prisión. Este tipo de situación expone los límites de las soberanías estaduales como mecanismo excluyente de protección de derechos y justifica, en nuestra opinión, una mayor injerencia de la comunidad internacional. Si el Estado no logra revertir patrones estructurales de desigualdad, difícilmente esté en condiciones de invocar su autonomía a fin de resistir el escrutinio internacional de derechos humanos. De allí que planteamos que son precisamente estos asuntos los que justifican una mayor injerencia internacional sobre los procesos internos. La apertura de la instancia internacional en este tipo de conflictos no puede verse exclusivamente como una amenaza para la autonomía de los Estados nacionales. Es común que tenga también un efecto estabilizador, por la ampliación de los ámbitos institucionales en que pueden ser planteados, discutidos y procesados ciertos conflictos colectivos que no logran ser dirimidos adecuadamente en los espacios sociales y políticos locales, entre otros factores, por el fuerte desequilibrio de poder entre los actores involucrados ${ }^{49}$.

La garantía básica de los derechos en situaciones de desigualdad estructural marcan, en nuestra opinión, la prioridad y el sentido político del $\mathrm{SIDH}$ en la etapa posterior al fin de las transiciones, en un escenario de democracias constitucionales caracterizado por el déficit de las instituciones y por la amplitud de las brechas sociales. El abordaje de esta temática, lejos de debilitar al SIDH o de desfigurar la noción de derechos humanos, contribuye a definir un núcleo duro de cuestiones prioritarias que le dan al sistema un renovado sentido en el contexto regional.

En cierta medida, las críticas a la intervención del SIDH en estas nuevas agendas están reflejando con frecuencia no solo una mirada acotada del proceso de internacionalización de los sistemas jurídicos locales sino también las limitaciones y carencias de las políticas públicas de muchos gobiernos latinoamericanos. Incluso gobiernos que han sido enérgicos y ejemplares en relación con el legado de las dictaduras, pero que no alcanzan a relacionar otro tipo de problemas urgentes, como la violencia carcelaria y la desigualdad social, con las políticas de derechos humanos.

Esta ampliación de la agenda del SIDH y el cambio de enfoque reseñado, que pone el acento en los problemas estructurales, así como en las políticas públicas y los remedios de alcance general, requiere una institucionalidad básica para el propio SIDH que desafía las restricciones 
de diversa índole que enfrenta en la actualidad. El tema tiene enorme complejidad y no vamos a cubrir aquí todos los aspectos que deberían ser discutidos. En lo que sigue, procuraremos solo enunciar algun.os asuntos que entendemos relevantes para una discusión estratégica sobre el funcionamiento del SIDH.

\section{ARTICULACIÓNYTENSIÓN ENTRE ELROL JUDICIAL Y EL ROL POLÍTICO}

En nuestra opinión, una de las principales tensiones institucionales que enfrenta el SIDH y en especial la CIDH tiene lugar entre la ampliación del cúmulo de casos y la necesidad de preservar y ampliar su rol de supervisión de la situación de derechos humanos en los países. Como vimos en la etapa de las transiciones y en la actualidad, la CIDH se plantea dar seguimiento a situaciones generales, a patrones estructurales y a las políticas de protección de derechos humanos de los Estados. Pero la dinámica de actuación del SIDH parece en ocasiones marcar un límite ante la posibilidad de articular adecuadamente casos y supervisión, rol cuasi judicial y rol político.

La cantidad de denuncias recibidas por año ante la $\mathrm{CIDH}$, como surgiere el gráfico 1, ha crecido de manera ininterrumpida en los últimos años. Es el resultado de algunos factores positivos ya enunciados, como un mayor conocimiento del sistema y el éxito de sus intervenciones en ciertos países, lo que le ha conferido una fuerte legitimidad. Pero también es el resultado de numerosos factores negativos, entre los que podemos mencionar la persistencia de un alto nivel de violaciones de derechos humanos por las diferentes agencias estatales y las serias deficiencias de los sistemas de administración de justicia en varios países del continente.

\section{Gráfico 1. Total de denuncias recibidas por año}

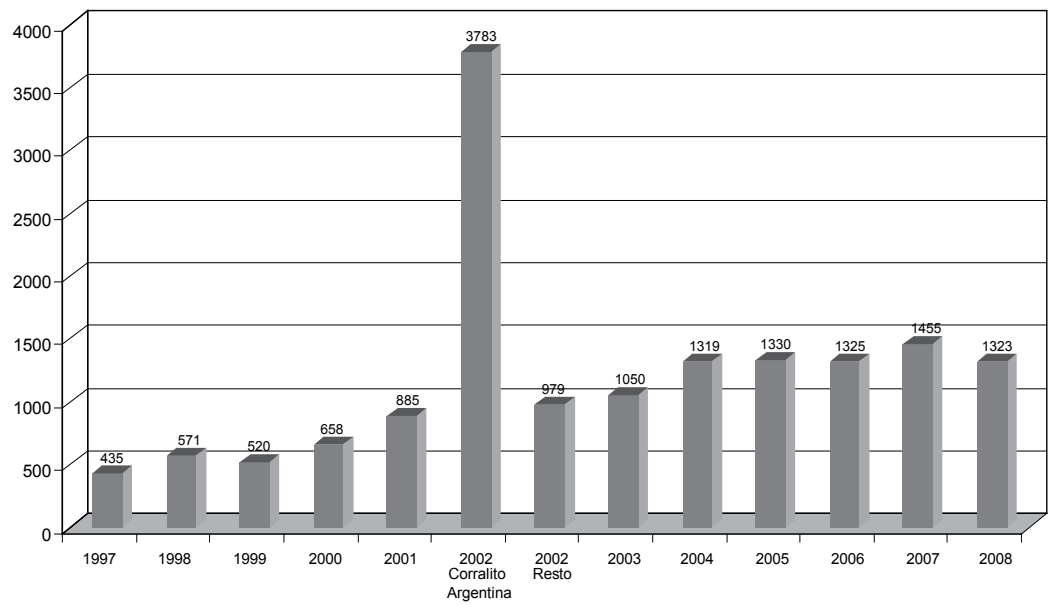

Fuente: $\mathrm{CIDH}$ 
En el gráfico 1, aparece que la cantidad de denuncias recibidas por el SIDH ha aumentado año tras año, ante lo cual se ha instalado, desde principios de la última década, por encima de las mil denuncias por año, sin retroceso. El promedio de casos en los últimos años de la década del noventa, entre 1997 y 2001, era de 600 por año; mientras tanto, el promedio actual, entre 2003 y 2008, se ha estabilizado en 1.300 casos por año.

En algunos países, el cúmulo de casos ha tenido directa relación con el resultado de algunos casos previos; ello, en alguna medida, ha hecho al sistema víctima de su propio éxito. Así, el aumento de peticiones en casos peruanos tiene directa vinculación con el caso «5 Pensionistas» de la Corte sobre reformas del sistema de seguridad social. Miles de pensionistas acudieron al SIDH ante el rechazo de sus reclamos en instancias locales. En el gráfico también se observa la presentación, solo en 2002, de 3.783 denuncias relacionadas con el congelamiento de los depósitos bancarios en Argentina por abogados particulares familiarizados con el uso del SIDH.

El aumento progresivo de la cantidad de denuncias se ha producido sin que la CIDH haya logrado aumentar sustancialmente su capacidad de procesamiento y evaluación de esas denuncias, lo que acumuló un significativo atraso procesal. Si bien el ritmo de evaluación aumenta cada año, la capacidad operativa limitada no logra reducir significativamente el atraso procesal de arrastre. En este punto hay que señalar que el sistema sigue funcionando con el mismo promedio de recursos financieros de la década pasada, e incluso ha sufrido recortes presupuestarios importantes en algunos períodos en los aportes estatales, vacíos que fueron cubiertos con cooperación internacional privada y por Estados donantes que no integran el sistema, tales como países europeos. Esto produce un fuerte atraso en la tramitación de los expedientes y afecta sensiblemente la efectividad de la labor de supervisión, si se la analiza en función exclusivamente del sistema de casos. En el año 2006, la CIDH creó un grupo de registro para enfrentar ese tema con financiamiento externo y avanzó en el estudio y en la tramitación de expedientes demorados, pero el atraso procesal sigue siendo un problema operativo grave.

En el gráfico 2 se observa la cantidad anual de peticiones abiertas a trámite por la Comisión: esto es, las denuncias que presentan a primera vista elementos suficientes para ser tramitadas y que, por lo tanto, se envían en traslado al Estado se mantienen estables desde los años noventa. En relación con la cantidad de denuncias recibidas por año en la actualidad (gráfico 1), representa en promedio el 10\% de estas.

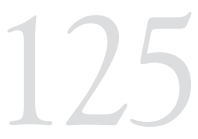

DE LAS

VIOLACIONES

MASIVAS A

LOS PATRONES

ESTRUCTURALES:

NUEVOS

ENFOQUES

Y CLÁSICAS

TENSIONES EN

EL SISTEMA

INTERAMERICANO

DE DERECHOS

HUMANOS 


\section{Gráfico 2. Peticiones abiertas a trámite por año}

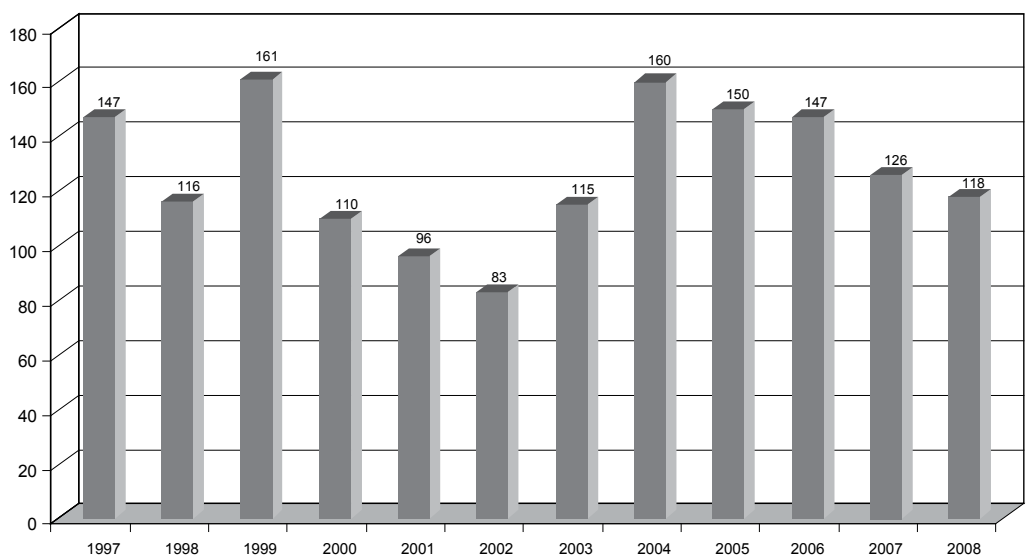

Fuente: $\mathrm{CIDH}$

En el gráfico 3 se indica el aumento de la cantidad de casos sometidos por la Comisión ante la Corte.

\section{Gráfico 3. Cantidad de casos sometidos por la Comisión ante la Corte}

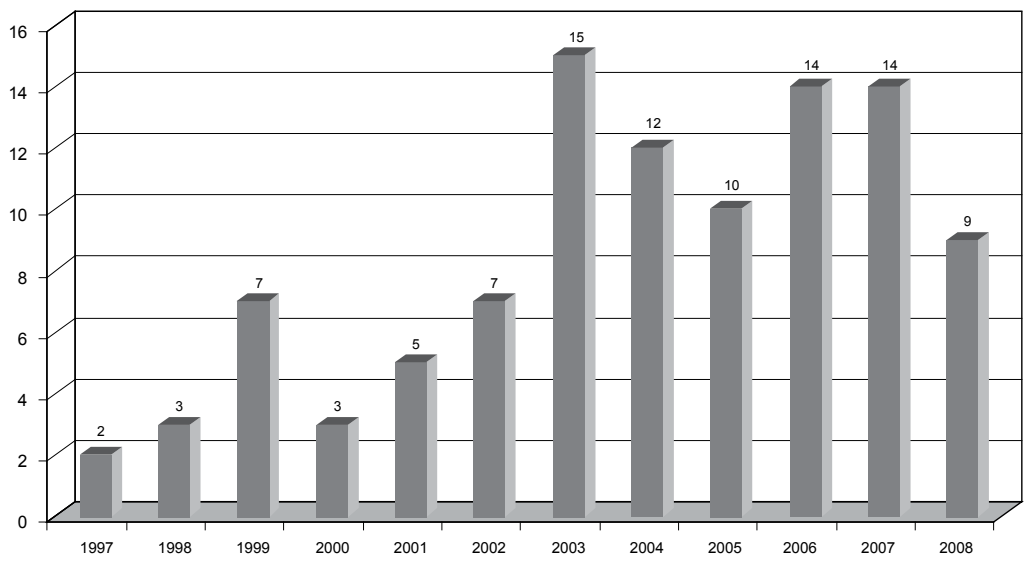

Fuente: $\mathrm{CIDH}$

De dos casos en 1997 a quince en 2003 y, a partir de allí, una cantidad promedio de 12,3 casos por año en el período 2003 a 2008: esto marca un aumento de la cantidad de casos que ingresa a la Corte, en particular desde la reforma de reglamento de la $\mathrm{CIDH}$ de $2001^{50}$. Sin embargo, si lo comparamos con el total de peticiones que ingresan por año a la Comisión (gráfico 1), se puede concluir que el promedio de casos que llegan 
a la Corte sigue siendo muy bajo, de alrededor del 1\% de las denuncias recibidas por año, que es más o menos el promedio histórico del SIDH desde la década de 1990.

El aumento de la cantidad de casos enviados y decididos por la Corte tiene un aspecto positivo, pues ha contribuido a desarrollar criterios jurisprudenciales claros y precisos en una amplia gama de asuntos, incluso sobre temas de procedimiento. En particular, la jurisprudencia de la Corte es más completa y ayuda a contar con criterios sobre los asuntos que se presentan a consideración de la $\mathrm{CIDH}$, y brinda también pautas más claras para la argumentación de los peticionarios y los Estados. Es difícil definir tendencias en relación con la tramitación de casos, pero en mi opinión las decisiones de la CIDH y de la Corte tienen en la actualidad mayor desarrollo conceptual, mayor rigor y coherencia jurídica, y procuran basarse en los precedentes o apartarse de ellos de manera fundada. Esto confiere mayor certeza a los usuarios del sistema y mejora la transparencia de los mecanismos. Estos cambios han ido acompañados de una mayor profesionalización de las secretarías de la CIDH y de la Corte IDH.

La enorme cantidad de casos ha provocado también, en mi opinión, una tendencia no siempre positiva a judicializar la actuación de la Comisión, que como dijimos es un órgano que desempeña además un rol político de supervisión que excede el tratamiento de casos contenciosos. Esta «tendencia a la judicialización» no se genera por un aumento de la cantidad de casos ante la Corte. No se trata de una judicialización a la manera del sistema europeo, por una mayor incidencia de la Corte en desmedro de la CIDH y de la tarea de supervisión política. Este argumento, que es planteado por algunos Estados, no tiene correlato en las estadísticas. Como vimos, existe un aumento de la cantidad de casos que llegan a la Corte desde la reforma de 2001, pero también se registra un aumento simultáneo de la cantidad de denuncias que recibe el SIDH por año, de modo que se preserva el promedio histórico del 1\% de judicialización ante la Corte, sobre el total de las denuncias recibidas en el SIDH. La participación de la Corte en el total de asuntos del SIDH sigue siendo limitada en cuanto a la cantidad de casos en los que interviene. Esto determina una tasa muy baja de judicialización ante la Corte, inferior incluso al promedio de casos que estudian y deciden los tribunales supremos y cortes constitucionales de los Estados, que suele ser de aproximadamente el 10\% de los presentados.

Hablamos aquí de judicialización en otro sentido: los informes sobre casos y medidas cautelares suelen cubrir una parte muy importante del tiempo de los comisionados y del equipo de trabajo de la secretaría de la CIDH; ello deja un tiempo muy reducido para el desarrollo de la función promocional y la planificación estratégica de su rol de supervisión, lo que suele provocar algunas tensiones. La economía del tiempo de la $\mathrm{CIDH}$ no es un tema meramente administrativo; cada año, por ejemplo,

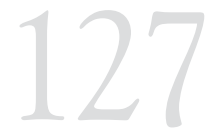

DE LAS

VIOLACIONES

MASIVAS A

LOS PATRONES

ESTRUCTURALES:

NUEVOS

ENFOQUES

Y CLÁSICAS

TENSIONES EN

EL SISTEMA

INTERAMERICANO

DE DERECHOS

HUMANOS 
se celebran habitualmente alrededor de cien audiencias durante sus períodos regulares de sesiones. En la fijación de esas audiencias, compiten directamente los casos y las solicitudes de audiencias sobre situaciones de derechos humanos en los países.

Es verdad que existen algunas sinergias entre el rol judicial y el rol político que deben incorporarse al análisis de situación. Los casos que llegan al sistema ayudan al diagnóstico de situación en los países. Las peticiones reiteradas sobre ciertos asuntos son una «señal de alerta», y el registro de casos funciona de alguna manera como una «caja de resonancia» de ciertos conflictos extendidos y a veces de problemas estructurales, así como de las deficiencias o debilidades de las respuestas institucionales ${ }^{51}$.

Pero el sistema de casos no puede ser la única fuente de información para definir las prioridades temáticas del SIDH. Los casos no representan la totalidad de los temas centrales en un país y además su conformación está también determinada por la posibilidad de ciertas víctimas de llegar con sus reclamos a la instancia internacional. En tal sentido, expresan también las limitaciones y problemas de acceso a la justicia del mismo sistema interamericano. De allí que muchas veces los casos reflejan la agenda de las organizaciones sociales con mayor capacidad de acción en este ámbito internacional, he incluso la narración de ciertos conflictos locales en función del enfoque que le dan estas organizaciones y que no tiene por qué ser la misma perspectiva que adopte el SIDH.

El litigio de los casos tampoco permite cubrir en su complejidad y profundidad los principales problemas de derechos humanos, pues en el caso se suelen recortar aspectos importantes de los conflictos colectivos, más allá de que, según vimos, el SIDH procura cada vez más observar patrones y pautas estructurales en casos particulares.

La Comisión y las organizaciones sociales han procurado, como señalamos, adaptar el litigio de casos a sus estrategias de incidencia en políticas públicas, de modo que, en la mayoría de los casos, reciben el tratamiento de un «litigio paradigmático». Los casos individuales suele ser la plataforma para el debate de cuestiones de interés público que trascienden la situación particular de las víctimas y su reparación, tales como el cuestionamiento de prácticas, políticas de gobierno y patrones estructurales. Por lo demás, en los últimos años ha crecido sustancialmente el litigio de casos colectivos: esto es, casos en los cuales se plantea la afectación de un grupo o de una «clase» de víctimas por la acción u omisión de un Estado. Como ejemplo de ello puede mencionarse los casos sobre pueblos

51 Este diagnóstico de situación construido a partir del docketde casos sería una herramienta útil para otros actores regionales y locales, si la CIDHen especial mejorara y refinara su sistema estadístico, y clasificase mejorlosasuntosplanteadosencadapetición:quiénessonlosusuarios,quétipodeproblemasestructurales sedenuncian, etcétera. Nose trata deemitir juiciossobrecasosen trámite, sinode aprovecharelcúmulode información disponibleen los legajos decasos paramejorar la labor desupervisión y promoción delaCIDH y brindar información que puede ser relevante para la comunidad de derechos humanos en la región. 
indígenas, así como las recientes medidas provisionales dispuestas por la Corte en materia carcelaria ${ }^{52}$ y sobre comunidades negras ${ }^{53}$.

La última reforma del Reglamento de la Corte ha ampliado considerablemente la posibilidad de las víctimas y las organizaciones no gubernamentales que las representan. Ahora estas pueden presentar ante la Corte sus propios alegatos y ofrecer su propia prueba, aunque en su demanda deben sujetarse a los hechos planteados por la Comisión. Los representantes de las víctimas tienen, además, plena legitimación procesal en la etapa de reparaciones y suelen fijar sus propios pedidos en cuanto al tipo de medidas de reparación no económica que debería fijar la Corte. En esta etapa se discuten, por ejemplo, reparaciones de alcance general, como el cambio de normas legales o de políticas públicas. Es indudable que esa mayor participación de las víctimas y de las organizaciones que las asisten enriquece el debate y permite disponer medidas de reparación que poseen un rol central en el fortalecimiento de las instituciones nacionales, con lo cual contribuyen, en cierta medida, a compatibilizar el rol judicial con el rol político o promocional del SIDH.

La incorporación de la voz de las víctimas y las organizaciones peticionarias en el litigio ante la Corte introduce la perspectiva y la «teoría del caso» de los demandantes particulares. A partir de la consolidación de esta tendencia, se ha abierto una discusión sobre la necesidad de que la $\mathrm{CIDH}$, gradualmente, reformule su rol en el litigio ante la Corte. Ello otorgaría a los peticionarios un lugar central y preservaría un lugar más estratégico, como una suerte de ministerio público, para la formulación de asuntos de interés general que estén involucrados en el caso particular. Así, por ejemplo, se podrían señalar aquellos temas estructurales o generales que subyacen a la violación de derechos de las víctimas individuales de un caso, de modo que se aporte un enfoque más amplio que, al mismo tiempo, contribuya a articular mejor su función cuasi judicial con su rol político. La CIDH debería preservar la posibilidad de sugerir a la Corte medidas de reparación de alcance estructural, como cambios de leyes, de prácticas y de políticas, y el país demandado aportaría también su diagnóstico sobre la situación de derechos humanos. Este cambio de rol podría consolidarse solo en aquellos casos en los que los derechos de las víctimas estuvieran resguardados y se asegurara un adecuado equilibrio procesal con los Estados.

Una estrategia importante que ha buscado la Comisión para articular el sistema de casos con su tarea promocional es la creación de relatorías

52 Entre otras puede verse Corte IDH, Asunto de la cárcel de «Urso Branco» respecto de Brasil, resolución del 18 de junio de 2002 y última resolución del 2 de mayo de 2008; Corte IDH, Asunto de las penitenciarías de laprovincia de Mendozarespecto de Argentina, resolución del22 denoviembre de 2004 y última resolución del 17 de octubre de 2008; Corte IDH, Asunto de las personas privadas de libertad de la penitenciaría «Dr. Sebastiao Martins Silveira» en Araquara, São Paulo, respecto de Brasil, resolución del 28 de julio de 2006y última resolución del 25 de noviembre de 2008; Corte IDH, Asunto de los niños y adolescentes privados de la libertad en el «Complexo de Tatuapé» da FEBEM, respecto de Brasil, resolución del 17 de noviembre de 2005 y última resolución del 25 de noviembre de 2008.

53 CorteIDH,AsuntocomunidadesdelJiguamiandóy delCurbaradórespectodeColombia, resolucióndel7de marzo de 2006 y última resolución del 5 de febrero de 2008.

DE LAS

VIOLACIONES

MASIVAS A

LOS PATRONES

ESTRUCTURALES:

NUEVOS

ENFOQUES

Y CLÁSICAS

TENSIONES EN

EL SISTEMA

INTERAMERICANO

DE DERECHOS

HUMANOS 
temáticas. Las relatorías, además de interiorizarse en los casos, realizan un trabajo de diagnóstico y seguimiento de los temas específicos de su competencia e impulsan actividades de incidencia de la Comisión sobre las políticas nacionales que los afectan, tales como visitas in loco, audiencias de situación general e informes temáticos. Esta actividad permite la utilización, en ocasiones, de los casos en trámite para avanzar con las discusiones sobre temas que la relatoría considera prioritarios en su propia agenda de diálogo con los Estados y la sociedad civil. De tal manera, la Relatoría sobre Pueblos Indígenas se ha involucrado en una serie reciente de casos tramitados ante la Corte sobre propiedad comunitaria de territorios ancestrales y participación política. La Relatoría Especial para la Libertad de Expresión ha definido, como un tema central de su agenda, la despenalización de la crítica sobre temas de interés público; y, además de analizar este tema en sus informes y comunicados de prensa de manera frecuente, ha acompañado el litigio ante la Corte de algunos casos que procuran avanzar en los estándares del SIDH en este campo. Las decisiones logradas servirán en el futuro como marco conceptual para el trabajo de la relatoría en este tema, y así mejorar la articulación de estrategias judiciales y de promoción ${ }^{54}$.

También puede observarse esa articulación entre los informes temáticos de la Relatoría sobre Derechos de las Mujeres y los casos tramitados ante la CIDH sobre violencia estructural, discriminación y denegación de acceso a la justicia. También la Relatoría sobre Afro-Descendientes y Discriminación Racial ha comenzado gradualmente a iluminar aspectos particulares de discriminación racial en casos de violencia contra comunidades negras en algunos países.

La búsqueda de articulación del rol judicial y del rol político no es solo una estrategia desarrollada por las relatorías temáticas, sino también por las relatorías a cargo del seguimiento de la situación en los países. Así, por ejemplo, el seguimiento que la CIDH ha realizado en los últimos años sobre las actividades de grupos paramilitares en Colombia, sus crímenes masivos y el alto grado de impunidad de sus acciones en la justicia colombiana, además de ser considerado en informes de país y en el informe anual de la CIDH, y estar en la agenda de supervisión de los relatores de país, fue ilustrado por una serie de casos paradigmáticos presentados ante la Corte IDH. En esos casos no solo se fijaron estándares jurídicos claros sobre la responsabilidad estatal por los crímenes del paramilitarismo, sino que se analizaron problemas estructurales del funcionamiento de las instituciones judiciales, como la justicia penal militar y el fuero contencioso administrativo. Más recientemente, la CIDH y varios peticionarios pidieron a la Corte IDH que se pronunciara sobre aspectos de la ley de justicia y paz que rige el proceso de desmovilización de paramilitares colombianos. La CIDH, al mismo tiempo, como parte de su rol político, realizó un seguimiento del proceso 
de desmovilización y un acompañamiento de la misión MAPP/OEA en Colombia; se pronunció sobre aspectos jurídicos del marco normativo, pero también sobre problemas concretos de implementación de la ley de justicia y paz. De este modo, la misma cuestión se abordó y discutió en el contexto de los casos ante al Corte IDH y en la agenda de supervisión de la CIDH. En tal sentido, la jurisprudencia que fue fijando la Corte en diferentes asuntos como el alcance del deber de investigación penal, las medidas adecuadas de protección de víctimas y de testigos, la naturaleza y características de las reparaciones a las víctimas de los grupos paramilitares y la responsabilidad del Estado colombiano al respecto, tuvo un enorme peso en las discusiones internas sobre el alcance de las normas que rigieron la desmovilización y las políticas públicas adoptadas en ese proceso $^{55}$. La CIDH empleó la jurisprudencia de la Corte como base de sus análisis en sus diálogos con agencias del Estado, en sus pronunciamientos públicos y en sus informes ${ }^{56}$. También fue clave como marco de referencia por algunas agencias del propio Estado al formular recomendaciones al gobierno y al congreso, así como a la Comisión Nacional de Reparación y Reconciliación de Colombia $(\mathrm{CNRR})^{57}$, y sirvió como marco al trabajo de control que ejercieron las organizaciones de derechos humanos en Colombia ${ }^{58}$. Las sentencias de la Corte y las recomendaciones y lineamientos de la CIDH también fueron considerados en varios debates parlamentarios relevantes durante el proceso que todavía está en curso: no solo la discusión en el congreso de la Ley de Justicia y $\mathrm{Paz}$, sino también la reciente discusión sobre una ley general sobre reparaciones a las víctimas del conflicto.

Sin embargo, más allá de estas formas positivas de articulación, en un sistema caracterizado por la limitación de recursos, existe también tensión entre el uso de recursos para avanzar la tramitación de casos, frente al uso de recursos para las actividades de promoción, como visitas in loco, visitas a los países de las relatorías, audiencias de situación general o procesos de consulta y de elaboración de informes o estudios temáticos.

Las necesidades que se derivan de la gestión de los casos han predominado también en los criterios de contratación del personal de la secretaría ejecutiva y en su estructura de organización interna, que parece más adaptada a la lógica de un tribunal que de un órgano con dos competencias diferenciadas: cuasi judiciales y de supervisión. Un ejemplo es

55 Véase Corte IDH, Caso de la masacres de Ituango vs. Colombia, sentencia del primero de junio de 2006; y Corte IDH, Caso de la Masacre de la Rochela, 11 de mayo de 2007.

56 Véase $\mathrm{CIDH}$, «Seguimiento de la Comisión Interamericana de Derechos Humanos al proceso de desmovilización de las AUCen Colombia. Compendiodedocumentos publicados(2004-2007)", febrerode 2007. También CIDH, «Lineamientos principales para una política integral de reparaciones», 2008.

57 VéaseComisión NacionaldeReparacióny Reconciliación, «Recomendación decriterios dereparaciónyde proporcionalidad restaurativa», Bogotá, CNRR, abril de 2007.

58 Véase, por ejemplo, Rodrigo Uprimny, Catalina Botero, Esteban Restrepo y María Paula Saffon (editores). ¿Justicia transicional sin transición? Verdad, justicia y reparación para Colombia. Bogotá: Centro de Estudios de Derecho, Justicia y Sociedad, 2006; Díaz, Ana María y Carlos Alberto Marín R. (editores). Colombia: el espejismo de la justicia y la paz. Balance de la aplicación de la ley 975 de 2005. Bogotá: Comisión Colombiana de Juristas, 2008.

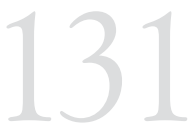

DE LAS

VIOLACIONES

MASIVAS A

LOS PATRONES

ESTRUCTURALES:

NUEVOS

ENFOQUES

Y CLÁSICAS

TENSIONES EN

EL SISTEMA

INTERAMERICANO

DE DERECHOS

HUMANOS 
el predominio de abogados en el equipo de trabajo de la secretaría y la inexistencia de un área que coordine y fije reglas metodológicas comunes para la elaboración de informes, visitas, y actividades de promoción y supervisión.

Además de la limitación de recursos, es común que se invoque el rol cuasi judicial para inhibir a la CIDH de intervenir o pronunciarse sobre temas que están siendo materia de estudio en el sistema de casos, para evitar eventuales prejuzgamientos. El abuso de este argumento puede conducir a actitudes conservadoras en el ejercicio de las facultades de supervisión. Lo que se contrapone es la necesidad de preservar la imparcialidad para decidir si existió en un caso una violación de derechos, frente a la necesidad de intervenir en situaciones en curso, a través de las vías de supervisión, como visitas, informes y posicionamientos públicos. Sin duda, esta cuestión presenta aristas complicadas y pone en evidencia la naturaleza particular de la $\mathrm{CIDH}$ que ejerce, al mismo tiempo, facultades que a veces resultan contrapuestas. La intervención retroactiva que apunta a reparar violaciones consumadas puede en ocasiones oponerse a otro tipo de intervención de índole preventiva, que actúe sobre situaciones en curso y que apunte precisamente a evitar que las violaciones se consumen o persistan en el tiempo.

La tensión entre el rol cuasi judicial y el rol político, propia de un órgano de protección híbrido con amplísimas competencias, caracteriza la dinámica de trabajo de la CIDH. Este tema merece sin duda una discusión profunda, y existe un debate sobre la necesidad de separar tajantemente los roles judiciales y políticos y reservar cada rol para un órgano en particular del SIDH. Es posible que este deslinde contribuya a brindar mayor claridad y certeza sobre los alcances de las competencias de la Comisión y de la Corte, lo cual eliminaría algunas de las tensiones antes mencionadas. Sin embargo, en nuestra opinión, gran parte del valor estratégico de la CIDH reside precisamente en la capacidad de articular esas funciones disímiles y de gestionar adecuadamente dicha tensión. Ello permite al sistema en su conjunto montar y ajustar en un único engranaje los casos y la supervisión, como dos vías conectadas para intentar incidir en los conflictos complejos y estructurales que caracterizan el escenario político regional.

\section{LA EFECTIVIDAD DE LAS DECISIONES. LA ARTICULACIÓN CON LOS SISTEMAS LOCALES DE JUSTICIA}

La autoridad de las decisiones y de la jurisprudencia de los órganos del sistema depende en parte de la legitimidad social alcanzada y de la existencia de una comunidad de actores interesados que acompañe y difunda sus estándares. No se trata de incidir a través de una fuerza coactiva — de la cual carece—, sino de una fuerza persuasiva que debe construir y preservar. 
Así, en los países en los cuales el Derecho internacional de los derechos humanos hace parte cotidiana del discurso jurídico y de los argumentos planteados en las cortes, tienen lugar algunos factores relevantes. Por un lado, el SIDH cuenta con un prestigio ganado a partir de ciertas acciones y decisiones que han marcado los procesos políticos del país. Por otro lado, existe una comunidad de actores sociales y políticos y de sectores académicos que se consideran protagonistas de la evolución del propio SIDH. En Argentina, por ejemplo, la incorporación de tratados de derechos humanos con jerarquía constitucional en 1994 fue un paso importante para ello, pero también lo fue el rol de la Comisión en su visita al país en plena dictadura militar en 1979, además de su informe, que contribuyó a fortalecer las organizaciones de víctimas y a desgastar al gobierno ante la comunidad internacional. En Perú también ha sido central la legitimidad ganada por la Comisión y la Corte en sus planteos de violaciones de derechos humanos durante el gobierno de Fujimori, lo que ha contribuido a conformar un sector de organizaciones sociales y de académicos, así como un núcleo de jueces y operadores jurídicos, familiarizados con el sistema.

Si bien en la última década se ha avanzado sustancialmente en la incorporación del Derecho internacional de los derechos humanos en el Derecho interno de los Estados, y si bien en varios países de la región la jurisprudencia de la Comisión y de la Corte se considera como una guía, e incluso como una «guía ineludible» para la interpretación de la Convención Americana por los jueces locales ${ }^{59}$, no se trata de un proceso lineal y existen voces disidentes. Recientes decisiones de los tribunales superiores en República Dominica y Venezuela relativizan la obligación de aplicación automática de las decisiones de la Corte IDH y procuran resguardar para las cortes nacionales una facultad de revisión previa (test de legalidad) acerca de la compatibilidad de la decisión del órgano internacional con el orden constitucional del país. Se trata de un debate abierto en los sistemas de justicia del continente, en el cual las posiciones refractarias a la incorporación del Derecho internacional de los derechos humanos tienen todavía un peso considerable.

Un factor importante para la consolidación de una mayor apertura de los sistemas de justicia nacionales a la aplicación del Derecho internacional es en mi opinión la conformación de una fuerte comunidad académica que discuta críticamente las decisiones del sistema y aporte insumos para el tratamiento de la jurisprudencia por los jueces y operadores jurídicos. Esta comunidad académica local y regional no solo es indispensable para asegurar la aplicación de los estándares interamericanos a nivel doméstico, sino también para obligar a rendir cuentas a los propios órganos del SIDH y presionar, por una mejora en la calidad, la consistencia y el rigor técnico de sus decisiones. Si bien existen claros avances en

DE LAS

VIOLACIONES

MASIVAS A

LOS PATRONES

ESTRUCTURALES:

NUEVOS

ENFOQUES

Y CLÁSICAS

TENSIONES EN

EL SISTEMA

INTERAMERICANO

DE DERECHOS

HUMANOS 
los últimos tiempos, aún no es posible afirmar que esa comunidad exista a nivel regional. Las decisiones de la Corte y de la Comisión son poco comentadas, muy poco criticadas y en varios países escasamente conocidas. Los tímidos debates originados en los últimos tiempos han obligado a replantear al menos a nivel teórico algunas premisas. Solo como ejemplo es interesante plantear los cuestionamientos que, desde la dogmática penal tradicional, se han formulado al alcance de los deberes de persecución penal de graves violaciones de derechos humanos establecidos en la jurisprudencia del SIDH y sus consecuencias sobre algunas garantías de los imputados, como el principio de cosa juzgada y ne bis in idem ${ }^{60}$, así como las discusiones que un sector de la doctrina constitucional formula al valor de autoridad de las decisiones de los órganos internacionales de derechos humanos; estos cuestionan el déficit democrático de dichos órganos internacionales o su falta de conocimiento de los procesos que ocurren en el interior de las comunidades políticas nacionales ${ }^{61}$.

Es verdad que el nivel de cumplimento de las decisiones particulares en el SIDH es importante en relación con las medidas reparatorias, y también respecto de medidas de reformas legislativas que fueron ya mencionadas. En ambos casos, algunos estudios preliminares sugieren que el nivel de cumplimiento más alto tiene lugar en el marco de los procesos de solución amistosa en los que el Estado, de manera autónoma, se fija compromisos de esta índole.

Sin embargo, los principales problemas de incumplimiento tanto de las recomendaciones de la CIDH cuanto de las sentencias de la Corte IDH están en las medidas de investigación penal de crímenes de Estado, en particular cuando los procesos internos se han cerrado y su reapertura puede afectar las garantías de los acusados. En algunos países, se observa un grave deterioro de las instancias judiciales con niveles de impunidad generalizados, esto es, que no se limitan a los casos de violaciones a los derechos humanos. Hemos visto cómo el SIDH ha utilizado el examen de patrones estructurales de impunidad para invalidar decisiones judiciales que intentan clausurar la investigación de este tipo de crímenes,

60 Véase, por ejemplo, Margarell, L. y L. Filippinı. (editores). El legado de la verdad. La justicia penal en la transición peruana. Lima: ICTJ e IDEHPUEP, 2006.

61 GaRgarella,R. «Justiciapenalinternacionalyviolacionesmasivasdederechoshumanos».En Delainjusticia penalalajusticiasocial.Bogotá:UniversidaddeLos Andes ySiglodelHombreEditores, 2008. Elautor repasa algunoscuestionamientosquepuedenformularsedesdeunateoríadelademocraciadeliberativaalvalorde autoridaddelasdecisionesdeórganosinternacionalesdeprotección,muchosdeloscualesadmitimoseneste artículo.Proponeunaseriedeproblemasconstitucionalesydedéficitdemocráticoquelosinternacionalistas no solemos plantearnos. Ello pese a presentar una visión a mi juicio un tanto esquemática del proceso social, políticoyjurídicocomplejoquecondujoalaconstrucción denuevosconsensos paralainvalidación de las leyes de amnistía por el congreso y la justicia en Argentina. Para una crítica de algunas objeciones "comunitaristas" a la aplicación del Derecho internacional de los derechos humanos en Argentina, véase Aвramovich, V. «Editorial». Nueva Doctrina Penal, 2007-B. También puede seguirse el debate entre Carlos F. Rosenkrantz y Leonardo Filippini. Véase al respecto Rosenkrantz, Carlos F. «En contra de los préstamos y otros usos no autoritativos del Derecho extranjero". Revista Jurídica de la Universidad de Palermo, año 6, $\mathbf{N}^{\circ}$ 1, octubre de 2005, pp.71-95; FILIPPINI, Leonardo. «EIDerechointernacional de los derechos humanos noes un préstamo. Reflexiones sobre la crítica a los préstamos de Carlos F. Rosenkrantz" y RosenkRANTZ, Carlos F. «Advertenciasaun internacionalista(olos problemas deSimón y Mazzeo)». Ambosen RevistaJurídicade la Universidad de Palermo, año 8, N 1, septiembre de 2007, pp. 191-213. 
por lo general para beneficiar a grupos con poder y en perjuicio de ciertos sectores de víctimas ${ }^{62}$.

No se ha avanzado de manera significativa en mecanismos internos de implementación de decisiones de los órganos del $\mathrm{SIDH}^{63}$. Esto en particular resulta un obstáculo cuando se trata de la imposición de obligaciones positivas. El trámite de un caso internacional y el cumplimiento de las medidas de reparación fijadas requieren un alto nivel de coordinación entre diferentes agencias de gobierno que no suele alcanzarse. Esto dificulta sensiblemente el trámite del caso, el trabajo de los órganos del SIDH y el cumplimiento de las decisiones. La coordinación en el interior del mismo gobierno es compleja, pero más lo es la coordinación del gobierno con el parlamento o la justicia, cuando las medidas involucradas en un caso requieren reformas legales o la activación de procesos judiciales. El tema es aun más grave cuando se trata de coordinar agencias del Estado nacional con Estados provinciales en sistemas federales.

La Comisión y la Corte realizan un informe a la Asamblea de la OEA sobre los incumplimientos, pero el tiempo con el que cuentan para plantear y activar los mecanismos de garantía colectiva de los Estados es mínimo. Tampoco existe un debate serio en el ámbito del sistema sobre cómo mejorar los mecanismos de cumplimiento de índole política y alcanzar un mayor compromiso de los diversos órganos de la OEA.

El mecanismo más efectivo hasta ahora para lograr resultados en el cumplimiento es la creación de instancias de supervisión internacional como las audiencias de seguimiento ante la Comisión o la Corte. Muchas organizaciones que representan víctimas prefieren estos mecanismos de supervisión internacional a los sistemas de ejecución internos, pues entienden que volver al ámbito nacional implica devolver a las víctimas a una situación de desequilibrio de poder con el Estado que solo la participación del órgano internacional puede evitar ${ }^{64}$.

Otro punto a considerar cuando se examinan los obstáculos de la efectividad del sistema es el tipo de remedios que se disponen como medidas de reparación en los casos contenciosos o en el marco de las medidas cautelares o provisionales. Muchas veces los remedios fijados

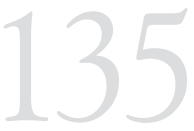

DE LAS

VIOLACIONES

MASIVAS A

LOS PATRONES

ESTRUCTURALES:

NUEVOS

ENFOQUES

Y CLÁSICAS

TENSIONES EN

EL SISTEMA

INTERAMERICANO

DE DERECHOS

HUMANOS

62 En el caso Carpio Nicolle contra Guatemala, la Corte IDH ha considerado el concepto de "cosa juzgada aparenteofraudulenta»enfunciónnosolodelascircunstanciasdelprocesojudicialenestudio,sinotambién del contexto y de la existencia de un «patrón sistemático de impunidad» de ciertos crímenes de Estado. Nuevamente, hay aquí una perspectiva que apunta a examinar desigualdades en la aplicación de la ley penal en beneficio de ciertos sectores privilegiados o en perjuicio de otros sectores sociales sojuzgados. En este caso, la desigualdad ante la ley es el fundamento de la descalificación de la decisión judicial de cierre del proceso y eso permite relativizar también el principio de cosa juzgada y de ne bis in idem. Puede consultarseelcompletoartículode KRSTICEVIC, Viviana. «Reflexionessobrelaejecucióndelasdecisionesdel sistema interamericano de protección de derechos humanos». En L. Tojoy V. Krsticevic (coordinadoras). Implementación de las decisiones del Sistema Interamericano de Derechos Humanos. Jurisprudencia, normativa y experiencias nacionales. Buenos Aires: CEJIL, p. 15-112.

63 ColombiayPerúhansancionadonormassobreimplementaciónycoordinaciónintergubernamentalqueson un modelo a considerar.

64 Véasealrespecto AвREgúM.yO.EsPINOZA. «LaeficaciadelaComisiónInteramericanade Derechos Humanos y la aplicación de sus decisiones por los Estados parte". En V. Aвramovich, A. Bovino y C. Courtis. Op. cit., pp. 191-216. 
en los casos obedecen a las sugerencias de los peticionarios y representantes de las víctimas y no existe una línea jurisprudencial consistente sobre esto. Otro problema es que el sistema sigue pensando y diseñando remedios bajo el modelo elaborado en el tiempo de las transiciones; pone así más énfasis en la investigación y determinación de responsables de las violaciones y menos en la modificación de los problemas estructurales que esas violaciones evidencian. Este sistema de remedios clásicos no encaja plenamente en el tipo de conflictos propios de la nueva agenda a la que hacíamos referencia. Sobre todo cuando el SIDH no se limita a juzgar hechos ocurridos en el pasado, sino que procura prevenir la consumación de daños o el agravamiento de situaciones en curso, o pretende incidir en la reversión de patrones sistemáticos o superar deficiencias institucionales. Ello ha quedado expuesto, en mi opinión, con mayor claridad en el marco de las medidas provisionales de la Corte en materia carcelaria. Estos asuntos en los que se plantea la existencia de condiciones inhumanas de detención y prácticas estructurales de violencia toleradas por autoridades estaduales y federales funcionan como una suerte de «hábeas corpus» colectivo internacional. En ellos se ha desarrollado un interesante debate sobre el tipo de remedios y los mecanismos de supervisión internacionales y locales. La Corte, a instancia de los peticionarios y de la Comisión, ha ido modificando gradualmente el tipo de remedios impuestos al Estado federal y, por su intermedio, a los Estados provinciales, pero aún no se ha conseguido un cumplimiento adecuado de las órdenes establecidas. La lógica de los remedios fijados se asemeja a los remedios del litigio de reforma estructural en los tribunales nacionales. En este tipo de casos, se procura equilibrar numerosos intereses contrapuestos y dar al gobierno un margen para definir medidas, mediante la presentación planes de acción de mediano y largo plazo. Se busca, además, resguardar el acceso a la información, y la participación de las víctimas y sus representantes en los procesos que definen esas políticas ${ }^{65}$. Una discusión abierta guarda relación con si estas medidas de supervisión internacional pueden ser efectivas sin involucrar activamente al propio sistema de justicia doméstico y a órganos públicos nacionales que estén en condiciones de realizar una evaluación y fiscalización de la situación carcelaria permanente en el terreno ${ }^{66}$.

La persistencia de bajos niveles de efectividad de este tipo de remedios estructurales puede conducir a un replanteo de todo el SIDH y traer costos en término de legitimidad de la Corte. Lo cierto es que el SIDH

65 Véanse las siguientes obras: SABEL, C. y W. SIMON. «Destabilization Rights: How Public Law Litigation Succeeds». Harvard LawReview, 117:1016,2004; Gauri, Varuny Daniel M. Brinks. «ANew Policy Landscape: LegalizingSocialandEconomicRightsintheDevelopingWorld».EnVarunGauriy DanielM.Brinks(editores). Courting Social Justice: Judicial Enforcement of Social and Economic Rights in the Developing World. Nueva York: Cambridge University Press, 2008; АвRAmovich, V. «El rol de la justicia en la articulación de políticas y derechos sociales". En V. Abramovich y L. Pautassi (compiladores). La revisión judicial de las políticas sociales. Estudio de casos. Buenos Aires: Editores del Puerto, 2009, pp. 1-91.

66 Véase el caso «Lavado, Diego Jorge y otros c. Provincia de Mendoza sobre acción declarativa de certeza». CorteSupremade Argentina, 6 de septiembre de2006. Setrata de la decisión de la CorteSupremaArgentina que discute la implementación de las medidas provisionales dispuestas por la Corte IDH en el asunto de Penitenciarias de Mendoza respecto de Argentina. 
ingresó en una etapa de desarrollo de un modelo de litigio estructural de protección de grupos o colectivos, sin haber afinado y discutido con profundidad los límites o potencialidades de sus reglas procesales ${ }^{67}$, su sistema de remedios y sus mecanismos de seguimiento y supervisión de decisiones.

El debate sobre la efectividad de la supervisión internacional está relacionado directamente con una cuestión vital para la calidad de los procesos democráticos: la pobre actuación de los sistemas de justicia locales.

En el gráfico 4 se observa un análisis temático del total de peticiones recibidas en la CIDH durante 2008 y surge claramente el lugar central que ocupan los problemas relacionados con el funcionamiento de los sistemas judiciales nacionales: alrededor del $62 \%$ de las denuncias contienen esta temática. Dentro de la cuestión justicia, un 23\% denuncia violaciones de debido proceso en el ámbito penal, $15 \%$ en materia laboral y $9 \%$ en procesos administrativos.

\section{Gráfico 4. Análisis temático del total de peticiones recibidas} en la CIDH durante 2008

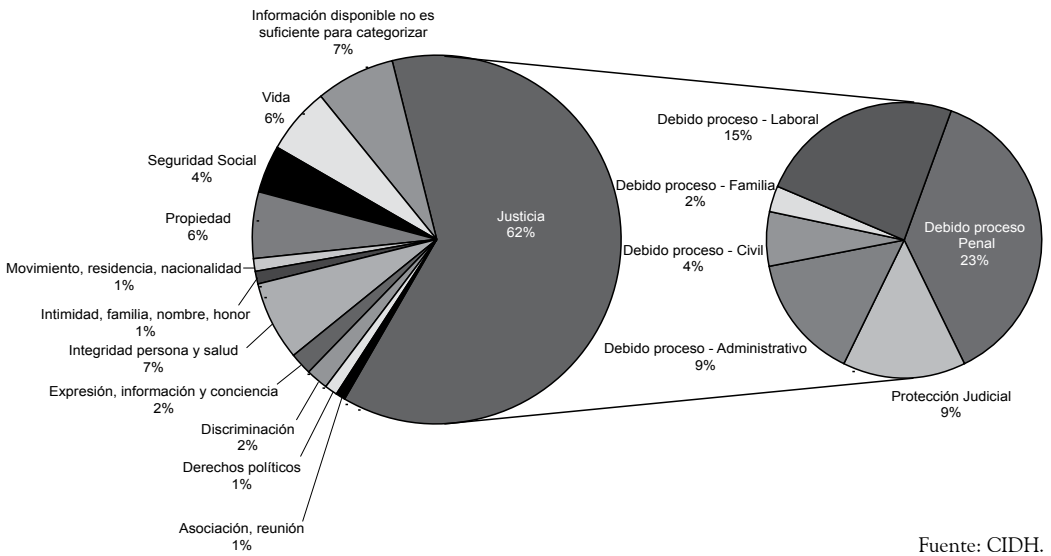

DE LAS

VIOLACIONES

MASIVAS A

LOS PATRONES

ESTRUCTURALES:

NUEVOS

ENFOQUES

Y CLÁSICAS

TENSIONES EN

EL SISTEMA

INTERAMERICANO

DE DERECHOS

HUMANOS

Indudablemente, una estrategia central para optimizar la efectividad del SIDH es trabajar en mejorar la respuesta de los sistemas nacionales de administración de justicia. El SIDH ha dado pasos importantes en este camino al fijar algunos principios claros acerca de qué debe entenderse por tribunales independientes o imparciales, plazo razonable de los procesos, uso excepcional de la prisión preventiva, alcance de la

67 Porejemplo,existeun debatesobreel gradodeprecisiónqueserequiereen laidentificación delas víctimas en casos de índole colectiva. Se necesita, en todos los casos, nombrar a cada persona afectada; de lo contrario,elSIDH,queingresóeneltratamientodepatronesestructuralesyelreconocimientode «derechos de grupos", debe adaptar sus procedimientos a esta nueva agenda y aceptar la identificación de grupos o "clases» comovíctimas, en especialen laetapade reparacionesyenelmarco de las medidas de protección cautelar.Elriesgoesunaciertaesquizofrenia,oundesarrolloendireccionesopuestas,entrelajurisprudencia sobre igualdad y las decisiones en materia procesal. 
cosa juzgada, revisión judicial de decisiones administrativas, entre otros temas. Una mejor sistematización de esta jurisprudencia podría servir como marco orientador de las políticas de reforma judicial en la región, y ello mejoraría la tutela de los derechos en los sistemas judiciales locales. El seguimiento de los sistemas judiciales nacionales debe seguir ocupando un espacio prioritario en la agenda de supervisión política de la $\mathrm{CIDH}$.

El desarrollo de obligaciones positivas en el campo de los derechos humanos, así como de derechos que pueden presentar una dimensión colectiva, exige al mismo tiempo determinar con mayor precisión qué debe entenderse por recursos idóneos y efectivos para protegerlos. Un sistema adecuado y accesible de acciones colectivas - como amparos colectivos, «mandatos de securança», acciones de clase-y de mecanismos de protección cautelar urgente puede promover un litigio local de interés público que permita dirimir en los tribunales nacionales muchos conflictos que hoy se dirimen en el escenario internacional. La promoción de vías judiciales para el litigio local de interés público, en asuntos de derechos humanos, es por lo tanto también estratégica para el SIDH.

\section{CONCLUSIÓN}

Es indudable que el SIDH cuenta con importante legitimidad, originada en su labor de desestabilización de las dictaduras, y luego en su rol inverso, definido como el acompañamiento de los procesos de transición hacia la democracia. En este artículo, planteamos que en el actual escenario político de América Latina el valor estratégico del SIDH consiste en su contribución al fortalecimiento de las instituciones democráticas, en especial de la justicia, y a los esfuerzos nacionales para superar los actuales niveles de exclusión y desigualdad. Para ello, además de la solidez de su jurisprudencia y del desarrollo de su sistema de peticiones individuales, el SIDH debe considerar su rol político y poner la mira en los patrones estructurales que afectan el ejercicio efectivo de derechos por los sectores subordinados de la población. Para lograrlo, deberá resguardar su función subsidiaria de los sistemas nacionales de protección y procurar que sus principios y estándares se incorporen no solo en la doctrina de los tribunales sino en la orientación general de las leyes y las políticas de gobierno. 